\title{
Spontaneous Symbol Acquisition and Communicative Use By Pygmy Chimpanzees (Pan paniscus)
}

\author{
Sue Savage-Rumbaugh \\ Department of Biology, Georgia State University \\ Yerkes Regional Primate Research Center, Emory University \\ Kelly McDonald, Rose A. Sevcik, and William D. Hopkins \\ Language Research Center, Georgia State University \\ Elizabeth Rubert \\ Yerkes Regional Primate Research Center, Emory University
}

\begin{abstract}
Two pygmy champanzees (Pan paniscus) have spontaneously begun to use symbols to communicate with people. In contrast to common chimpanzees (Pan troglodytes) using the same communicative system, the pygmy chimpanzees did not need explicit training in order to form referential symbolobject associations. Instead, they acquired symbols by observing others use these symbols in daily communications with them. In addition, the pygmy chimpanzees have begun to comprehend spoken English words and can readily identify lexigrams upon hearing the spoken words. By contrast, common chimpanzees who received similar exposure to spoken English are unable to do so. The older pygmy chimpanzee has begun to form requests of the form agent-verb-recipient in which he is neither the agent nor the recipient. By contrast, similarly aged common chimpanzees limited their requests to simple verbs, in wihch the agent was always presumed to be the addressee and the chimpanzee itself was always the recipient, thus they had no need to indicate a specific agent or recipient. These results suggest that these pygmy chimpanzees exhibit symbolic and auditory perceptual skills that are distinctly different from those of common chimpanzees.
\end{abstract}

\section{What's in a Name?}

The language acquisition capacity of apes has been the focus of a number of research projects (Asano, Kojima, Matsuzawa, Kubota, \& Murofushi, 1982; Fouts, 1972; Gardner \& Gardner, 1971; Hayes \& Hayes, 1951; Kellogg \& Kellogg, 1933; Miles, 1983; F. Patterson, 1978; Premack, 1971; Rumbaugh, 1977; Savage-Rumbaugh, 1984b, 1986; Terrace, 1979). Despite the differences among various projects regarding the communicative systems (American Sign Language [ASL], geometric sym-

This research was supported by National Institutes of Health Grants NICHD-06016 and RR-00165 to the Yerkes Regional Primate Research Center, Emory University.

The authors wish to thank Duane Rumbaugh for his constant help, advice, guidance, and colleagueship throughout the study; without him the work never would have been possible. His comments on various drafts of the manuscript also made it a much better article.

We also wish to thank Mary Ann Romski for being such a good friend to Kanzi, and for conducting the blind field test, in spite of the fact that she was not fond of woods. Her keen attention to Kanzi's communications are responsible for the success of the test.

Jeannine Murphy and Phillip Shaw worked daily with Kanzi and Mulika throughout this entire period and helped them learn the many things described in this paper. They were, and are, essential to the well being and development of Kanzi and Mulika.

Correspondence concerning this article should be addressed to Sue Savage-Rumbaugh, Yerkes Regional Primate Research Center, Emory University, Atlanta, Georgia 30322. bols, or plastic tokens) used, it is generally agreed that apes can learn to produce symbols in order to bring about the occurrence of desirable events (Jolly, 1985; Savage-Rumbaugh, 1984b; Terrace, 1985).

It has also been shown that when a chimpanzee is systematically taught the communicative skills of requesting, labeling, and comprehending, indicative referential symbol usage can then appear without further training (Savage-Rumbaugh, 1984b, 1986; Savage-Rumbaugh, Pate, Lawson, Smith, \& Rosenbaum, 1983). With the appearance of indicative usage, apes go beyond conditioned request-oriented utterances and become able to make statements about behaviors they are going to engage in, in advance of actually emitting those behaviors. The ability to use symbols to orient the attention of others to particular aspects of the environment, other than the fulfillment of immediate needs, also appears to accompany the onset of indicative communication (Savage-Rumbaugh, 1984b, 1986; Savage-Rumbaugh et al., 1983).

Nonetheless, it is still the case that the manner in which apes learn language skills differs from the way in which the human child learns language. That is, apes have generally required special training sessions during which they are reinforced for producing the correct symbol in the presence of a particular object. During such training sessions, they are repeatedly shown an object, or engaged in an activity, then required to name that object or that activity (Fouts, 1972; Gardner \& Gardner, 1971; Premack, 1976; Rumbaugh, 1977).

One ape, Loulis, (an infant adopted by Washoe) has been observed to produce a number of hand gestures without specific 
human training (Fouts, Hirsch, \& Fouts, 1982). However, Loulis has not been tested to determine whether he in fact understands the referents of any of these gestures. Because it is well documented that both captive and wild chimpanzee populations learn various nonreferential gestural signals (McGrew \& Tutin, 1978), it may be that Loulis' gestural capacities do not function any differently from those of other captive apes who use simple nonreferential gestures (Savage-Rumbaugh, 1984a, 1986; Savage-Rumbaugh et al., 1983; van Lawick-Goodall, 1968). In any case, until Loulis's abilities are appropriately assessed, we cannot conclude that he has learned referential signs.

It is possible for apes, and for language-disabled children, to use gestures appropriately, without being able to comprehend the gestures at the referential level. In such cases it can be argued that the individuals in question have not made the transition from associative naming to representational naming (Rice, 1980; Savage-Rumbaugh et al., 1983). Similarly, the earliest gestural and vocal symbol usage in normal children is primarily associative. It is only in a gradual manner that words become representational and context independent (Lock, 1980).

It is this transition from associative to representational symbol usage that is the critical issue for the proper understanding of language use in both apes and children. As Lock (1980) put it:

The child's early learning of words presents two main problems for investigation. Firstly, how does the child come to associate specific sounds with specific objects. Secondly, when does he transcend these associations and come to use these sounds to refer to objects; for transcend these associations he must if his use of sound is to qualify as language. (p. 108)

\section{Lock elaborates:}

The second problem is the more difficult one to tackle; when does the child pass beyond simple associations and come to use sounds to name objects? The major difficulties presented by this problem are conceptual: what are the characteristics of the acts of naming, and what criteria are there that can be used to judge the status of some noise the child makes? (p. 113)

Lock does not offer absolute criteria for judging whether a particular instance of symbol usage is associational or representational. Instead, he attempts to describe the various phases of word usage that the child passes through during the transition from associational to representational usage. The first phase is characterized by ritualized games in which the mother initially plays both her own role and the role she wants the child to assume. For example, she poses questions to the child and then answers the questions for the child. When the child begins to enter into such games, it is typically by uttering various sounds in direct response to maternal questions. After the child has begun to respond in turn, consistently reproducible sounds begin to occur. For example, a common ritual in our culture is naming pictures in children's books. According to Lock (1980), children often begin to respond to queries about such pictures with a specific sound before that sound acquires any meaning beyond its performance in the ritualized picture-naming situation.

The transition to the representational phase begins when the child becomes able to initiate and to structure the games by himself or herself. Coupled with such self-initiation is the emer- gent ability to respond with appropriate behaviors to the symbol usage of others, in the absence of context-dependent gestures or routines. For example, the child passes from being able to respond to his mother's request to "get your ball" only when the ball is in front of him, to being able to stop what he is doing and go out of the room to retrieve a ball upon request.

When the first reports that apes could learn symbols appeared (Gardner \& Gardner, 1971; Premack, 1971; Rumbaugh, 1977), the process by which children began to use words was not well understood, nor was the distinction between associational usage and representational usage widely recognized. Apes did learn to produce symbols reliably in association with various objects, events, structured routines, and so forth. However, unaware of the way in which the other components of referential symbol usage emerged, ape language researchers quickly concluded that apes were both using and comprehending symbols in a referential manner (Gardner \& Gardner, 1971; Premack, 1976; Rumbaugh, 1977).

Later work revealed that these assumptions were premature and that apes tended to stay at the associational level of symbol usage unless they received training designed to foster the specific subskills that appeared to precede the emergence of representational symbol usage in human children (Savage-Rumbaugh, 1984b; Savage-Rumbaugh et al., 1983). For example, Savage-Rumbaugh (Savage-Rumbaugh, 1984b, 1986; SavageRumbaugh et al., 1983) reported teaching chimpanzees to use symbols to request various foods and activities, yet when then asked to label these same foods and activities, the specific associations between symbol and referent became blurred. Moving from requesting to naming is accomplished far more easily in the human child (Lock, 1980). For example, if a child requests a teddy bear, but instead the mother holds up a duck and asks "Can you tell me what this is?"- -the child is able to set aside her own interest in obtaining a teddy bear long enough to respond appropriately to the question, and as she does so, she does not become confused about which sounds are associated with the object she desires and which are associated with the object she is being asked to name. By contrast, this ability to differentiate between naming and requesting did not appear spontaneously in Sherman, Austin, or Lana, the three common chimpanzees used in the Savage-Rumbaugh (1986) study. Unlike children, they could request things that they were unable to name, and they could name things that they were unable to request. They then needed explicit training, using fading techniques, in order to make a similar transition between requesting and naming.

It was also the case that Sherman and Austin, unlike children, did not progress on their own to the point of being able to go off in search of a particular item in response to the symbolically encoded request of another party. They needed special training on this task, and it was necessary to begin by limiting such requests to one of three items immediately in front of them. Only after a year and a half of practice were they able to travel unaccompanied to another room and to return with a requested item as children begin to do at about 18 months (Lock, 1980).

It was not until after Sherman and Austin were taught to (a) differentiate requesting from labeling, and (b) retrieve absent objects in response to the requests of others that they began spontaneously to display representational (as opposed to associational) symbol usage (Savage-Rumbaugh, 1986). Nonetheless, 
when representational usage did appear, it followed the same path that Lock observed in human children. That is, Sherman and Austin began to initiate word games by singling out objects and showing the correct symbol without prompting. They also began to extend their symbol usage beyond the ritualized settings. For example, Austin used the symbol scare (originally learned in the context of a social game of covering one's face with a mask and pretending to scare another) to refer to a chimpanzee outside the lab that was screaming loudly as he was carried past the window of our building. Third, they began to acquire new symbols without explicit training and also to assign new symbols themselves to new foods or new tools that were introduced. Fourth, they were able to make categorical judgments about objects when presented with only symbolic information, in the absence of the referent (Savage-Rumbaugh, 1981; Savage-Rumbaugh, Rumbaugh, Smith, \& Lawson, 1980).

The weight of the evidence to date suggests that apes tend to learn symbols in an associational manner, and they need explicit systematic training in order to enable them to use symbols referentially and to respond appropriately and competently as listeners. However, once they are given such training, their symbol usage begins to take on an increasingly representational character until finally they are able to use symbols to convey intended actions.

\section{Understanding Spoken English Words}

It has been suggested that apes lack the vocal and/or neurological apparatus to produce speech as we know it (Lieberman, 1984), but this, of course, still leaves open the question of whether they can understand speech. Comprehension typically precedes production by a period of 6 months or longer in the normal child (Benedict, 1979; Hirsch-Pasek, Golinkoff, Fletcher, Beaubien, \& Cauley, 1985). Presumably during this period of comprehension, the child learns a number of different semantic functions as well, so that by the time a word is produced, its usage reflects a relatively sophisticated conceptual base. However, when individuals are taught to produce words before there is any evidence that they comprehend the word, their usage may reflect little more than a stimulus-response bond (Rice, 1980).

Both Gardner and Gardner (1971) and Terrace (1979) asserted that the comprehension skills of Washoe and Nim far outpaced their production skills. However, none of their reports contained measurements of comprehension in which the chimpanzee was asked to select one object from a group in response to the production of a given sign. Instead, estimates of comprehension were inferred from situations that did not rule out gestural or visual pointing cues. There have also been assertions that apes can understand spoken English (Fouts, Chown, \& Goodin, 1976; F. Patterson \& Linden, 1981). Close inspection of the data reveals that the evidence is limited to a few phrases that have been drilled in contextually specific situations (Fouts et al., 1976) or the data are so incomplete that it is not possible to determine precisely which words the ape may comprehend (F. Patterson \& Linden, 1981).

In the Fouts et al. (1976) study, a chimpanzee (Ally) was taught to produce 10 different behaviors in response to 10 different English phrases. It is noteworthy that although Ally was reared in a human home from birth, and immersed in an English-speaking environment, he did not show reliable behavioral responses to the 10 English phrases when they were first introduced in the study. A pretraining period was needed during which Ally was taught to respond to specific phrases such as "Ally bring me the pillow." The total number of phrases to which Ally produced reliable responses was small and none of the utterances were tested independently of contextual cues.

Much more dramatic claims for English comprehension have been made for Koko, a lowland gorilla raised with exposure to both speech and sign from an early age (F. Patterson \& Linden, 1981). The evidence for these claims comes from a single administration of the Assessment of Children's Language Comprehension (ACLC; F. Patterson \& Linden, 1981). This test evaluates language skills by presenting the subject with four line drawings and a sentence. When this test is given to normal children, older children typically "peak out", doing well on all aspects of the test. Younger children experience a rather steady decline in performance as they reach the more difficult levels of the test. Koko, by contrast, showed a very different pattern of performance, getting about half of the answers correct, regardless of the complexity of the sentences and the line drawings presented to her. Because Koko was as likely to identify a single element as she was to respond to a complex four-element sentence, it is difficult to interpret her test results.

The home-reared chimpanzees Gua (Kellogg \& Kellogg, 1933) and Viki (Hayes \& Hayes, 1951) were reported to be severely deficient with regard to the comprehension of speech. In fact, not only did they show limited and context dependent comprehension, but explicit attempts to teach word comprehension failed with both animals. Hayes (1951) observed that:

From time to time we . . tried to speed Viki's education by teaching her the meaning of words. On the whole, however, we . . . found it even harder to teach her language understanding than to test it. After more than eighteen months of coaching, we have not yet taught Viki to identify her nose, ears, eyes, hands and feet [in response to the spoken word]. (p. 229)

Viki's and Gua's limited comprehension of spoken English corresponds closely with the speech comprehension deficits that have been observed in Sherman and Austin (Savage-Rumbaugh, 1986; Savage-Rumbaugh, Sevcik, Rumbaugh, \& Rubert, 1985). Like Viki and Gua, their responses to speech seem to be situationally linked and heavily dependent on contextual cues such as routine, intonation, glance, and gesture.

It is often observed that the ability of a given species to produce different sounds is closely related to its capacity to analyze the same type of sounds (Lieberman, 1984). Moreover, it is thought that the ability to perceive speech categorically is limited to human beings (Lieberman, 1984). Some animals have been taught to recognize individual phonemes (Dewson, 1964; Kuhl \& Miller, 1975; Morse \& Snowdon, 1975; Sinnott, Beecher, Moody, \& Stebbins, 1975; Waters \& Wilson, 1976) or specific words produced with the same rhythm and intonation. However, even highly trained dogs (Warden \& Warner, 1928) have difficulty recognizing these sounds in the context of normal speech and, unlike children, dogs do not learn the meanings of words by listening to normal speech. They require training in 
which particular speech sounds are isolated and repeated many times while the dog is guided through the appropriate behavior. Additionally, although dogs learn to respond to commands such as sit, stay, and so forth, they apparently have difficulty learning to select a specific object from a group (Warden \& Warner, 1928). Responding with differential selection (but a similar motor pattern such as fetching) to the same array of objects on command appears to be more difficult than emitting a differential motor pattern to verbal cues. To date, dogs have not demonstrated such differential selection though sea lions, dolphins, and apes have done so (Herman, Richards, \& Wolz, 1984; Savage-Rumbaugh, 1986; Schusterman \& Krieger, 1984).

If an ape were to begin to comprehend spoken English without being so trained, and were able to do more than emit differential motor responses on cue, it would suggest that the ape possessed speech and language abilities similar to our own. Even if the ape were unable to speak, an ability to comprehend language would be the cognitive equivalent of having acquired language.

\section{Language Learning Without Training}

This study describes the first instance in which a nonhuman species has acquired symbols without specific training toward that goal. It also presents the first documented account of the comprehension of specific English words by apes. It is important to note that the present project was not undertaken with the intent of producing the findings described later. The findings were serendipitous. What follows is not an experiment but rather a description of events that lead us to the conclusion that Kanzi, one of the young ape subjects of this study, was acquiring symbols spontaneously at $2 \frac{1 / 2}{2}$ years of age. This description is followed by a developmental account of this phenomenon across the subsequent 17 months. Kanzi's younger half-sister, Mulika, began to use symbols at 11 months of age, and her behavior is also described. In general, Mulika's data corroborate the basic findings with Kanzi. At the time of writing, Mulika's symbol usage is limited when contrasted with Kanzi. However, Mulika began using symbols at a much earlier age and is presently far ahead of where Kanzi was at a similar age. Important differences between Kanzi's and Mulika's language acquisition and that of two common chimpanzees, Sherman and Austin, who were taught language with the same visual-graphic symbol system, are also discussed.

Although it is not widely recognized, there are four great apes species. Of these four, only the pygmy chimpanzee (Pan paniscus) has not, prior to this report, been the subject of language acquisition studies. This is primarily attributable to the difficulty in obtaining these animals. They are rare, both in captivity and in the wild, and it is presently illegal to export them from their severely threatened native habitat in Zaire.

Their social-communicative repertoire differs from that of the other great apes in a number of important dimensions. Eye contact, gestures, and vocalizations are considerably more frequent and more elaborate in Pan paniscus than in other apes (Savage-Rumbaugh \& Wilkerson, 1978; Savage-Rumbaugh, Wilkerson, \& Bakeman, 1977; Thompson-Handler, Malenky, \& Badrian, 1984). Male-female ties appear to be exceptionally close (Kuroda, 1984), and males, at least in captive groups, par- ticipate in infant care (T. Patterson, 1979; personal observation). Food sharing is a frequent behavior even between adults (Kuroda, 1984). By contrast, in the common chimpanzee the male-female ties are weak, the males do not participate in offspring care, and the majority of food sharing occurs only between mother-infant pairs (Kano, 1980; McGrew, 1975; van Lawick-Goodall, 1968; Wrangham, 1979). Because elaboration of the gestural, visual, and vocal domains of communication must have occurred in evolution prior to the emergence of speech proper, the more extensive development of these skills in the pygmy chimpanzee, in contrast to other apes, suggests that they might be better prepraed to acquire language.

Cognitive studies of Pan paniscus also suggest that they are brighter than other apes (Rumbaugh \& McCormack, 1967; Yerkes \& Learned, 1925). Yerkes (Yerkes \& Learned, 1925) raised a pygmy chimpanzee and a common chimpanzee together for several years, although at the time, the species difference was not recognized by anatomists. Yerkes, however, noted numerous physical and behavioral differences between the two animals, Chim (Pan paniscus) and Panzee (Pan troglodytes), and suspected that Chim was an extraordinary animal. If the pygmy chimpanzee is indeed a brighter species, this too would suggest a greater predisposition toward language acquisition. This article describes the initial results of the first longitudinal attempt to investigate the language acquisition capacity of a member of the species Pan paniscus and to contrast it with that of members of Pan troglodytes.

\section{Method}

\section{Subjects}

Ape language training requires in-depth longitudinal study and the rearing of a small number of animals. It is time and labor intensive and for these reasons only a small number of subjects can be involved in an ongoing study at any one time. This article describes the language acquisition skills of 2 Pan paniscus subjects. Where relevant, comparisons are made with 2 Pan troglodytes subjects who were reared in a language-using environment by people from 1975 to 1983 . The Pan paniscus subjects presently are being reared in a similar environment, but with access to their mother. Comparisons between these animals thus reflect data gathered across a 10-year time span.

The principal subject of this study is a young male pygmy chimpanzee, Kanzi, who was 4 years of age at the time of this report. Kanzi was born in captivity at the Yerkes Regional Primate Research Center, on October 28, 1980. Kanzi was assigned to the Language Research Center at 6 months of age, along with his mother, a wild-caught female, Matata, who also has served as a subject in previous studies of nonverbal communication (Savage-Rumbaugh \& Wilkerson, 1978; Savage-Rumbaugh et al., 1977). Kanzi's development of gestural capabilities is described elsewhere (Savage-Rumbaugh, 1984a).

Although this paper focuses on Kanzi's symbol usage, preliminary data are also presented on his younger sister, Mulika, born December 22, 1983. Mulika was temporarily separated from Matata at 4 months of age because of an eye infection. Like Kanzi, Mulika has become strongly attached to her human caretakers. Although both Kanzi and Mulika spend several hours a day with their mother and seek out her company for play and for affection, they elect to be with people most of the time.

Selected data are also presented on 2 Pan troglodytes males, Austin and Sherman. A detailed account of their training history is presented elsewhere (Savage-Rumbaugh, 1984b, 1986; Savage-Rumbaugh et al., 
1983). They were assigned to the Language Project at $1 \frac{1}{2}$ years and $21 / 2$ years of age, respectively, and were removed from their mothers before coming to the Language Research Center. They are now 9 and 10 years of age.

\section{Communication System}

The main medium of communication used with all of the animals is a visual symbol system (see particularly Rumbaugh, 1977; SavageRumbaugh, 1986). The system consists of geometric symbols that brighten when touched. This visual energy change is treated as the behavioral equivalent of uttering a word. Kanzi's present keyboards are connected to a speech synthesizer so that words are spoken when Kanzi touches the symbols on the board. A symbol can be touched repeatedly; each repetition will cause the speech synthesizer to produce the appropriate word. The speech synthesizer was added to Kanzi's keyboard after evidence was gathered which indicated that he comprehended spoken English words (see below).

The graphic symbol system was designed to compensate for the anatomical and neurological limitations (Lieberman, Crelin, \& Klatt, 1972 ) that apparently prohibit apes from producing humanlike vocalizations. Although Lana's (the first chimpanzee trained to use the system, see Rumbaugh, 1977) keyboard required the use of a specific grammar called Yerkish, this was not required for Sherman, Austin, Matata, Kanzi, or Mulika. Lana's symbols were also color coded according to semantic function, but this feature was dropped for all later subjects.

Continuing advancements in technology have led to numerous improvements in the keyboard system. Lana used one keyboard that was located in a stationary position. Sherman and Austin used three keyboards that were attached by extension cords to the computer. These cords made it possible to move their keyboards from room to room. Kanzi uses a similar keyboard indoors; however, when outdoors, he has used a variety of battery-powered boards that are attached to an Epson HX-20 computer and a portable Votrax synthesizer.

None of the battery-powered keyboards have proven rugged enough to stand up under constant field use. Consequently, most of the time in the field Kanzi and Mulika use a "pointing board," a thin laminated panel containing photographs of all of the lexigrams. Kanzi, Mulika, and the people with them point to the lexigram that they wish to use. Similar pointing boards were tried unsuccessfully with Sherman, Austin, and Lana. These three common chimpanzees tended to indicate symbols with such broad hand movements that it was difficult to determine which symbol they were attempting to select. Spoken English and gestures have been used with all subjects of both species. The spoken English accompanies most lexigram communications produced by the experimenters. Most gestures are informal and spontaneous. They serve as a natural adjunct to speech. Approximately 100 ASL gestures are also used by the experimenters, none of whom are fluent in ASL. The general approach to symbol usage is one that optimizes the process of communication regardless of modality. Any and all modalities are used to convey a given message, and any and all modalities are accepted from the chimpanzees as responses.

\section{Early Rearing and Exposure to Lexigrams}

Kanzi was first exposed to the use of graphic symbols, gestures, and human speech at 6 months of age while still being cared for by his mother. Kanzi remained with Matata constantly until he was $2 \frac{1}{2}$ years old, and during that time attempts were made to teach Matata eight symbols. Matata's early training was informal, in that her teachers modeled symbol use and encouraged her to use the keyboard in any way she wished. Initially, they did not use a trial-based training approach in which alternatives were systematically varied with the requirement that
Matata request the displayed alternative. Matata began using the symbols quickly, but did not develop an adequate concept of one-to-one correspondence between a given symbol and a given referent. Therefore, more formal procedures (identical to those that had proven effective with Sherman and Austin) were initiated.

No attempts were made to teach Kanzi symbols while his mother was in training because it was not feasible to separate them for teaching purposes and because Kanzi seemed disinterested in requesting food. He preferred to grab it away from his mother, or to nurse. Kanzi was permitted to observe Matata's training sessions, though we generally attempted to keep him otherwise occupied while Matata used the keyboard, because he tended to disrupt her attention.

Beginning at $1 \frac{1 / 2}{2}$ years of age, Kanzi started to show interest in the symbols. He often tried to grab them as they appeared on the video screen or the projectors, while Matata was using the keyboard to obtain food. Kanzi also lighted keys sporadically and then ran toward the vending device, suggesting that he had learned that touching symbols caused this device to dispense food.

Kanzi often interrupted his mother's training sessions by leaping on her head, her hand, or the keys, just as she was about to select a symbol. He would also leap on her hand just as she was reaching for a piece of food, grab it away, and run off. Generally, Matata tolerated this behavior, though at times she shoved Kanzi away. During this period, Kanzi did not engage in any behaviors that suggested that he knew that specific symbols were associated with specific foods. He did, however, spontaneously begin to use the chase lexigram to initiate chase games. This behavior appeared just shortly after he spontaneously began to use a gesture (hand clapping) for this same purpose.

Kanzi was separated from his mother at $2 \frac{1 / 2}{2}$ years of age so that she could join the Pan paniscus colony located at the Yerkes Field Station for breeding purposes. Matata became pregnant and returned to the Language Research Center 4 months later. At that time, Kanzi was reunited with her, but chose to spend the majority of each day with his human companions, even though he was allowed to be with his mother as much as he wished. His younger sister, Mulika, was born 9 months later.

Kanzi was interested in Mulika from the time of her birth and at 1 month of age, Matata allowed Kanzi to carry Mulika about. At 4 months of age, Mulika developed an eye infection and had to be removed from Matata for treatment. When Mulika was returned to Matata, she also chose to stay with human companions the majority of each day. Unlike Kanzi, Mulika did not have the opportunity to observe Matata during symbol training; however, she did have the opportunity to observe Kanzi.

\section{Rearing and Exposure to Lexigrams Following Separation From Matata}

In many respects, Kanzi's and Mulika's rearing environment, following separation from Matata, has been similar to that of Sherman and Austin. Like them, they are with people who use the visual symbol system around them throughout the day for a wide variety of communications. A number of the same teachers have worked with all 5 animals (Sherman, Austin, Matata, Kanzi, and Mulika). Some major differences between the environments and exposure to lexigrams are listed in the paragraphs that follow.

1. Sherman and Austin were introduced to lexigrams in a training, as opposed to an observational setting. Training, without the opportunity to observe, lasted 1 year. Beyond that time, they had many opportunities to observe and did acquire some symbols through observation.

2. Sherman and Austin's keyboard was not equipped with a speech synthesizer, because tests revealed that they did not understand spoken English words (Savage-Rumbaugh, 1986). Differential tonal cues were added to their keyboard instead. 
3. Sherman and Austin did not use a keyboard outside the laboratory, because their specificity of symbol use tended to decrease when they used a board that did not require a discrete response. Apart from the basic procedural differences listed above, other aspects of the rearing environment (attachment to caretakers, opportunity to interact with and observe people, exposure to human speech, exposure to gestures, photographs, novel objects, types of formal tests, discipline, opportunity to watch television, etc.) have been very similar (Savage-Rumbaugh, 1986).

Because Kanzi and Mulika began (a) using symbols without specific training, (b) identified these symbols regardless of their location, (c) did not tend to confuse symbols for similar items (such as apple, orange, and banana), and (d) comprehended spoken words, no formal training was ever attempted with them. (Details on these statements are presented later in the article.) Moreover, food reward was not made contingent on symbol acquisition.

Instead, people modeled symbol use during their communications with each other and with the chimpanzees. During all daily activities (playing, eating, resting, traveling in the woods, etc.) people commented on and emphasized their activities both vocally and visually by pointing to the appropriate lexigrams on the keyboard. For example, if they were engaged in a tickling bout, the teacher would comment "(teacher's name) tickle Kanzi" both via the keyboard and vocally. Sometimes Kanzi and Mulika observed people using the keyboard, and at other times they ignored the keyboard usage.

\section{Naturalistic Outdoor Environment}

During the warmer months of the year, food is dispersed daily to 17 named locations within a 55 -acre forest that surrounds the Language Research Center (see Figure 6). No food is available to them in the laboratory during this time so they must travel from place to place during the day with their human companions to obtain it. During warm months, most of the day is spent traveling outdoors. One or more foods are taken to each location (for example, bananas and juice are taken to the treehouse, peaches are taken to the lookout).

When Kanzi knew only a few food symbols, he was provided with photographs of foods so he would have a means of indicating which food he would like to eat. These photographs were placed on the ground at each location, and when Kanzi wished to travel elsewhere, he so indicated by selecting a photograph. Kanzi was then taken to the location where that food could be found. Within 4 months, Kanzi learned where all the foods were located and could not only select a photograph when he wanted to go to that location, but could also guide others to the appropriate place. He often carried the photograph the entire distance, frequently pointing to it and vocalizing on the way. Later, he began to use the keyboard to announce where he wanted to go, and we slowly ceased carrying the photographs into the woods. Mulika began traveling in the woods with Kanzi at 6 months of age. Kanzi often helped carry her for short distances. By her second summer she was old enough to share some of the foods that were obtained at different sites and had begun to use symbols to initiate travel herself on occasion.

Typically, Kanzi initiates travel to specific locations and obtains the food on arrival. However, when he does not indicate a desire to go anywhere, travel is initiated by people. During travel from place to place, if Kanzi does not choose to eat the food at a particular location, he is asked if he would like to have it placed in a backpack and carried along. If such queries are ignored, the food is left where it was found. If the query is responded to by a positive gesture, such as shoving the food toward the pack, or motioning toward the pack (positive gestures often are accompanied by positive vocalizations), then the food is carried along to other sites. Typically, after a half day's travel, a number of different foods have accumulated in the backpack. As this occurs, Kanzi's use of a word such as juice can refer either to the juice that has been placed in the pack or to a location that was left much earlier and is now far away. After indicating "juice" in such a situation, Kanzi will be queried as to whether he wants to go to the treehouse or if he wants to drink the juice that is in the pack. If he repeats "treehouse" after his companion, he will then gesture in the direction one must travel in order to reach the treehouse. If he seems to want the food in the backpack, he will approach the pack and touch it, often accompanying this gesture of indication with a vocalization.

Four months after the foods were first placed in the woods, when Kanzi was almost 3 years old, a blind test was run with an experimenter who had never been in the wooded area traveled daily by Kanzi. The experimenter did not know where any of the foods were located, where any trail was, or how to return to the laboratory from the woods. The test was conducted across two afternoons. During that time, she traveled from place to place with Kanzi, at Kanzi's initiative. Kanzi selected each location by pointing to either a photograph or to a lexigram. An array of 6 to 10 alternatives, either photographs or lexigrams representing both foods and locations, was presented to Kanzi at each stopping point. Kanzi made his selection from this array. He then proceeded to guide the experimenter to the location of the food he had selected.

\section{Indoor Environment}

Throughout the day, Kanzi and Mulika are asked to help in a variety of activities such as changing the bed sheets, doing the laundry, and preparing food. They repeatedly attempt to engage others in games of hide, Marco Polo, keepaway, chase, grab, tickle, or playbite and they often spontaneously attempt to help in simple projects such as wiping up spills, washing dishes, spraying the hose, scrubbing the floor, and moving items from one area to another. They travel from place to place inside the center, play with clay, bubbles, and toy dolls, watch special videotapes of people they know engaging in interesting activities and hiding favored objects, and occasionally are entertained by someone dressing up in an animal costume and paying them a visit. At night Kanzi usually asks to watch TV. A number of videotapes, with lexigram overlays, have been prepared that are of interest to the chimpanzees. These indoor activities are very similar to those that characterized Sherman's and Austin's free time (Savage-Rumbaugh, 1986; see also the videotape that is available with the book).

\section{Data Recording}

From the onset of Kanzi's lexigram usage at $2 \frac{1 / 2}{2}$ years of age, a complete record was kept of all of his utterances for 17 months. All lexigrams used by Kanzi, Mulika, and their companions are automatically recorded by computer-monitored keyboards when indoors. In the woods, lexigram utterances are recorded by hand and entered into the computer at the end of the day along with contextual notes. All data summaries in this article are based on the complete corpus of Kanzi's utterances from the time he was 30 months of age (and was separated from his mother) to 47 months of age, and upon the complete corpus of Mulika's utterances from 11 to 21 months of age.

Each utterance is classified when it occurs, first as correct or incorrect, and second, as spontaneous, imitated, or structured. Spontaneous utterances are those initiated by Kanzi or Mulika with no prior prompting, querying, or other behavior designed to elicit a specific utterance. Imitated utterances are those that include any part of a companion's prior keyboard utterance. Structured utterances are those that are initiated by questions, requests, or object showing behavior on the part of the companion. Structured utterances are usually preceded by a query such as "What is this?," "Which do you want?" or "Tell me first before you take this." In such instances, the person producing the query generally knows the correct answer to the question; such questions are not designed to gain new information. Rather, their purpose is to determine whether Kanzi or Mulika can give a specific answer. 


\section{Vocabulary Acquisition Criterion}

The criterion used for determining when a word should be listed as a member of Kanzi's and Mulika's vocabulary differs significantly from those used in other studies (Fouts, 1973; Gardner \& Gardner, 1971; Terrace, 1979). These criteria required that symbol production appear to be appropriate and that it occur on a specific number of consecutive days without prompting. Because it has been shown that context-appropriate responses can occur without comprehension (Savage-Rumbaugh, 1984b, 1986; Savage-Rumbaugh et al., 1983), a behavioral concordance measure was devised. This measure required that Kanzi and Mulika verify their utterances on 9 of 10 occasions. Only spontaneous utterances were considered to be appropriate candidates for behavioral verification.

For example, if Kanzi requested a trip to the treehouse he would be told: "Yes, we can go to the treehouse." However, only if he then led the experimenter to this location could a correct behavioral concordance be scored for the word treehouse. If Kanzi asked for a specific food, such as a banana, he would be presented with a number of favorite foods (apples, oranges, bananas) and note would be made of whether or not the requested food agreed with the selected food. Alternatively, a request for a banana might be acknowledged by agreeing that a banana should be obtained. Kanzi would then be asked to lead his caretakers to the location in the woods where bananas could be found. Because many foods are located in the woods, if he chose the correct trails and arrived at the bananas site, a positive concordance would be scored. On still other occasions, concordance could be obtained if a number of foods had been gathered from the field and were being carried in the backpack and Kanzi announced "banana," proceeded to search through the backpack, and pulled out a banana. Any of these means of behaviorally demonstrating knowledge of the correspondence between symbol and referent were considered to be sufficient for producing a concordance score. Similar means of scoring concordances were used with Mulika.

All correspondences were obtained in spontaneous situations that occurred naturally during the course of the events of any given day. If the situation in which a spontaneous utterance did not lend itself to obtaining a concordance (for example, if Kanzi touched the symbol banana and pointed to the backpack, when the only food in the backpack was a banana), the utterance was responded to appropriately, but a concordance was not scored.

A symbol was classified as a member of Kanzi's (or Mulika's) productive vocabulary only after it had occurred spontaneously on 9 of 10 occasions, followed by a demonstration of concordance on 9 of 10 additional occurrences. These occurrences did not need to be on consecutive days because it was observed that quite often Kanzi (and Mulika) did not tend to say the same things on 10 consecutive days unless we specifically set up contrived situations to encourage them to do so. In addition, the criterion for vocabulary inclusion was constantly updated. This meant that once a word became a member of Kanzi's or Mulika's vocabulary it could also drop out if, a any time, usage and behavioral demonstrations of correspondence dropped below the .90 criterion.

To make certain that we accurately recorded our data real time, an analysis was done of 4.5 hours of videotape in which we checked our real-time coding against the videotape. The scoring was done independently by two different observers, with one observer scoring the behavior real time and the other scoring the tape. At the time the scoring was done, the real-time observer did not know that the data would be used for a reliability check at a future date and thus the real-time scoring was not altered by the knowledge that this was a reliability check. Of the 37 utterances scored by both observers, there was $100 \%$ agreement with regard to which lexigrams Kanzi used and whether or not they were used correctly in context. There was one disagreement about the type of utterance, that is, whether it was structured or spontaneous. In addition, 9 utterances were noted on the videotape that were not seen by the real-time observer, suggesting that a number of lexigram usages are not noted during the busy flow of social interactions. Typically, when this happened, Kanzi was able to gain someone's attention by repeating himself. Of these 9 unobserved utterances, 8 were spontaneous and 1 was structured. All were correct given the context. No utterances were scored by the real-time observer that were not seen on the videotape.

\section{Tests of Productive and Receptive Capacities}

In addition to recording language-use behaviors as they occurred spontaneously, Kanzi and Mulika were also tested informally, in everyday situations. For example, if Kanzi were playing with some keys, he might be asked what they were. Conversely, if he had scattered a number of objects over the floor, he would be asked to help pick them up, retrieving first the ball, and then the blanket. If he failed any such tasks, he was simply shown what to do. Such requests were not used as drills, nor were they associated with rewards. Additionally, such informal tests were not given with new lexigrams, only with lexigrams that there was reason to believe that Kanzi or Mulika already knew.

At the end of the 17-month period covered in the present report, (when Kanzi was between 46 and 47 months of age) he was tested on all the items in his vocabulary at that time. Mulika was tested between 18 and 21 months of age. These tests served to control for the possibility that symbol usage was being inadvertently cued by contextual setting, inadvertent glances, and so forth. During these tests, the order of presentation and the location of stimuli were carefully controlled in order to preclude knowledge on the part of the experimenter that might inadvertently bias the response. (Prior to the test results reported here, Kanzi was also tested at 32 months of age on receptive skills, at 35 months of age on naming skills, and at $\mathbf{4 5}$ months of age on both naming and receptive skills. See Savage-Rumbaugh, 1986; Savage-Rumbaugh, Rumbaugh, \& McDonald, 1985; Savage-Rumbaugh, Sevcik, Rumbaugh, \& Rubert, 1985 for a more detailed discussion of these tests.)

Test trials were administered in the afternoons with between 20 and 40 trials presented in one session, depending on the amount of time spent playing between test trials. No test item was ever repeated during a given session, and no two trials were ever the same. The test items and alternatives were randomly determined on each trial with the requirements that neither the alternatives nor the test items were repeated on consecutive trials and that each item serve as both an alternative as well as a test item. Either three or four alternatives were present on every trial.

Thus Kanzi might be presented with the lexigrams greenbean, apple, and tomato and asked, in spoken English to, "Show me the tomato lexigram." Tomato was not repeated then as the target item during that session unless it was tested in a different manner. (For example, on another trial, Kanzi might be shown the tomato lexigram, and then presented with photographs of a banana, some M\&Ms, and a tomato.) However, two trials with the same target item never followed one another under any circumstances. Additionally, the same alternatives were never paired more than once with the same target item. The photographs were $3 \frac{1}{2}$ in. $\times 5$ in. $(8.9 \times 12.7 \mathrm{~cm}) 35-\mathrm{mm}$ color prints and several different photographs of each object were used. The lexigrams were 1 in. $\times 1$ in. $(2.5 \times 2.5 \mathrm{~cm})$ replicas of the lexigrams on the keyboard.

Photograph to lexigram. During this test the subject was shown a photograph and was asked to select, from a set of three alternatives, the proper lexigram for that photograph. The alternatves were presented behind a simple folding blind and were not visible to the experimenter. The placement of the alternatives in the blind was performed by a second experimenter so as to eliminate the possibility that the first experimenter's inadvertent glances toward the left, right, or center of the blind could be interpreted as potential cues. The subject made his selection by pointing to a particular lexigram. The response was observed by the first experimenter who then dropped the blind to determine whether or not the choice was correct. The second experimenter did not observe 
the subject as the response was made and the English name of the photograph was not spoken during this test.

Spoken English to photograph. In this test, the subject listened to the spoken English word and then selected the appropriate photograph from a set of three alternatives. The English word was usually presented in a sentence and then repeated, for example, "Kanzi, can you show me $X$ ? X." The subject responded by pointing to one of the photographs and the experimenter then lowered the blind to determine whether he or she was correct.

Spoken English to lexigram. This test was essentially the same as described above with the exception that the response alternatives were now lexigrams instead of photographs.

Synthesized speech to lexigram. This test followed the format of the above test, but the word was now produced by a Votrax Voice 2 Personal Speech System. The word was produced twice by the synthesizer, and then Kanzi was presented with four lexigrams. His task was to point to the alternative that corresponded to the synthesized word. The purpose of this test was to demonstrate that Kanzi was not responding to the intonation of natural human speech. The Votrax synthesizer used in this test is an inexpensive model that produces flat-sounding, machinelike speech. When analyzed spectrographically, words produced by the Votrax synthesizer are noticeably different from human speech in that individual syllables are much more discrete and the range of frequencies used to produce a given word is considerably smaller. A number of the words produced by the synthesizer are difficult for people to identify if they do not know what word they are hearing. This test has presently been administered only to Kanzi.

Formal tests of the same sort (with the exception of the synthesized speech) were also administered to Sherman and Austin. However, because the specific items in their vocabulary were not, in many cases, the same as those that Kanzi and Mulika had learned, the tests were not identical item for item. Also, because Sherman and Austin were unable to select photographs in response to spoken English words, they were not tested on their ability to pair lexigrams with spoken English words because we assumed that this task would be even more difficult for them. Neither Sherman nor Austin had, under any previous circumstances, shown an ability to select a lexigram when they heard the associated English word. They did not seem to like the trials in which the sample was spoken English, and this made such tests difficult to administer. Unlike Kanzi and Mulika, Sherman and Austin were rewarded for correct choices with food, as it greatly facilitated cooperative participation in their case.

\section{Results}

\section{Untutored Gestural Usage: Some Observations}

Between 6 and 16 months of age, both Kanzi and Mulika spontaneously began to use iconic gestures to communicate preferred directions of travel and actions they wished to have performed. For example, they used an outstretched arm and hand to point toward areas to which they wished to be carried; they made twisting motions toward containers when they needed help in opening twist-top lids; they made hitting motions toward nuts they wanted others to crack for them; and they requested that others retrieve items that they dropped by gesturing first toward the person, then toward the item. Gestures were often accompanied by vocalizations that served to orient the listener's attention and to convey affect. (For a more detailed discussion of Kanzi's spontaneous gestures and the importance of bipedal carriage in their development, see SavageRumbaugh, 1984a.)

Matata's use of gesture was much more limited than that of her offspring. She did not gesturally indicate desired direction of travel, nor did she iconically depict opening movements. She would, however, lead a person to a door that she wanted opened and point to the lock, or hand the person an empty bowl while making a food vocalization and gesturing to the bowl. She also used gestures and vocalizations to solicit aid from one person when she was angry at another person or chimpanzee. Occasionally, when Sherman and Austin displayed at her, she would place a hose in a person's hand and gesture toward them, as if attempting to get the person to spray them with water.

Similar gestures were observed in Sherman and Austin, but they appeared at a later age (between 2 and 4 years) and were not accompanied by affective vocalizations. Although a detailed comparison of the gestural differences between these two species must await comparisons of videotapes made at similar ages, some general conclusions can be drawn. Sherman's and Austin's gestures tended to occur in situations in which the person's attention was fully focused on them and the activity they were attempting to accomplish, such as opening a box to retrieve food or opening a door to gain access to other apes. Generally, they would try to accomplish this goal on their own, and if they failed, they would gesture toward the object while looking at a person to solicit help.

Kanzi's and Mulika's gestures were often more explicit than those used by Sherman and Austin. For example, if Kanzi wanted a very hard nut opened, he would toss it to a person. If the person did not understand that this was a request to crack the nut, Kanzi would then slap the nut with his hand. If the person still did not understand, Kanzi would take a small rock and place it on top of the rock and gesture toward the person to illustrate what he wished to have done. Mulika has been similarly emphatic. When wanting a balloon blown up, for example, she placed the balloon in a person's hand, pointed to the person's mouth, then pushed the person's hand with the balloon toward his or her mouth.

Sherman and Austin seemed unable to readily elaborate their gestures in such specific and innovative ways if the person failed to understand what they wanted. For example, at times, Sherman would scream as though he had seen something that had scared him and comment "scare" at the keyboard. (When especially frightened, he has lighted the symbols scare Sherman outdoors as a way of asking to leave the situation.) However, it was not always easy to determine what was scaring Sherman. When approached, Sherman would generally look in the direction of the fearful object. If the feared object, for example, a snake, was hiding and could not be seen by the person, Sherman was unable to be more specific unless the person acted in a concrete fashion by looking under objects in the general vicinity. Only when the person neared the correct object would Sherman emit "waa" calls. Sherman did little to guide the person's attention apart from gazing and orienting his body in a particular direction.

In a similar circumstance, Kanzi, instead of screaming, left the area to solicit help from a person. Approaching with his hair puffed out and a wide-eyed expression, he led the person back to the appropriate area and gestured directly toward the snake or other fearful object. This made it unnecessary to touch objects or to engage in other search behaviors in order to determine what was wrong. In addition, if one could not see anything 
where Kanzi was pointing, he would carefully move closer and gesture more explicitly.

\section{First Appearance of Lexigram Usage for Communicative Purposes}

Immediately following his mother's removal for breeding purposes, Kanzi started approaching the keyboard much more often to light symbols, and he now stopped and searched for a particular symbol, instead of just flailing his hands toward the board. Although it was assumed that Kanzi had learned (from watching his mother) that lighting symbols was a way of obtaining food, it was not assumed that he had formed any referential relation between particular symbols and particular foods, or even that he understood that particular symbols could be used to ask for particular foods.

His previous interest in his mother's keyboard activities had been sporadic. When he had touched lexigrams on her keyboard, he never seemed to be searching for a particular symbol. Even though it was not thought that Kanzi was purposefully selecting a particular symbol to ask for a certain food or activity, people responded to such keyboard utterances as though they were intentional. They were instructed to do so because language is viewed as a process of "guided reinvention" (Lock, 1980 ) in which it is the interpretation of a child's communications as intentional, long before they actually are, that facilitates the development of language for intentional communicative purposes (Clark, 1978; Gray, 1978; Lock, 1978; Shotter, 1978; Trevarthen \& Hubley, 1978). It is made clear to all personnel that the purpose of these "rich interpretations" is to promote communicative development, but not to evaluate it. This approach was also followed with Sherman and Austin.

The change in Kanzi's attitude toward the keyboard following his separation from Matata was unexpected. He appeared to be deliberately searching for particular symbols. Even more important, however, was the occurrence of behaviors that suggested that Kanzi had learned that particular symbols referred to particular items. For example, if Kanzi asked for an apple and he was presented with three fruits (an apple, a banana, and an orange) he would ignore the others and eat the apple. By contrast, if he had originally requested a banana and he was brought the same three fruits, he ate the banana and ignored the rest. Moreover, when these fruits were placed in front of Kanzi and he was asked to name the banana, the apple, or the orange (by touching the symbol at the keyboard as the experimenter spoke the English word), he was able to name the correct fruit, even when he was not interested in eating any of them.

It was also noted that Kanzi used symbols when he did not seem to be requesting anything, and in fact would not take an item even if it were offered. A few examples, taken from the daily notes just shortly after Kanzi was separated from Matata are given below:

1. Kanzi requested "apple" (by touching the symbol on the keyboard) and one was retrieved from the refrigerator for him. He took a few bites of it and then dropped it on the floor and began to do playful spins and other gymnastic maneuvers while grinning broadly. (Kanzi is very prone to engage in gymnastic play such as running, jumping, leaping, spinning, and diving.) Kanzi then suddenly stopped his spinning, touched "apple" again, and picked up the apple that he had dropped on the floor and took a bite of it. He then touched "chase" and looked toward the experimenter, who responded by chasing Kanzi around the room. Kanzi then stopped and touched "apple chase", and began running around the room with the apple tucked in between his leg and his abdomen while smiling and glancing back toward the experimenter.

2. After eating an apple and drinking juice, both of which he had requested at the keyboard, Kanzi again touched "juice", then picked up the juice, poured it out, and began stomping the apple and juice together while displaying a play face.

3. Kanzi touched "ball" and then began looking all over the room. Upon finally finding the ball, which had rolled under the keyboard, he displayed a play face, grabbed the ball, and started slapping it vigorously.

Mulika began using symbols at 12 months of age, much earlier than had Kanzi. As she did so, she entered a phase of symbol usage not seen in Kanzi in which she used a single symbol for many different things. She seemed to grasp the idea that the keyboard was a means of communicating before she realized that specific lexigrams communicated specific things. She began by using the lexigram milk for many different things, including requests to be picked up, requests for attention, requests to travel to different places, requests for food, and requests for milk. During this period of time, Mulika imitated people as they used other symbols to tell her the name of something, but whenever she spontaneously used the keyboard, she always selected milk.

She also combined the lexigram milk with gestures that helped make her intentions clear. This made it possible to determine what she meant, even though the lexigram milk was not related to her intended communication. For example, she would touch "milk", climb onto a person's shoulders and then gesturally direct them to take her outdoors. Or, if various foods were available, she would touch the milk lexigram and then point to the apple to indicate the food that she wanted. It is important to note that Mulika was not required to touch any symbol in such circumstances. Simply pointing to the apple and vocalizing, as she had done since she was quite small, would have been sufficient to obtain an apple. Thus it does not seem likely that Mulika was simply touching a symbol as a way to make things happen. Like Kanzi, Mulika did not experience difficulty identifying lexigrams in new positions, on other keyboards, or off the keyboard. From the time she began using milk she could select it from any array of lexigrams.

This generalized usage of the milk lexigram lasted approximately 2 months. After that time, Mulika began to use a number of other lexigrams appropriately. The second lexigram that appeared was surprise. It first occurred when Mulika was 14 months old and she had just been given some milk after touching the milk symbol and gesturing toward the refrigerator. She refused to drink the milk; instead Mulika went back to the keyboard and began to search it very carefully. She then touched the surprise lexigram and looked to see if anyone was watching. An unusual unnamed food was found in the refrigerator and given to Mulika. She proceeded to consume it with relish. In the next few months the words surprise, Matata, peanut, hotdog, coke, mushroom, melon, cherry, banana, jelly, go, and blueberry all began to appear and were used for specific and appro- 


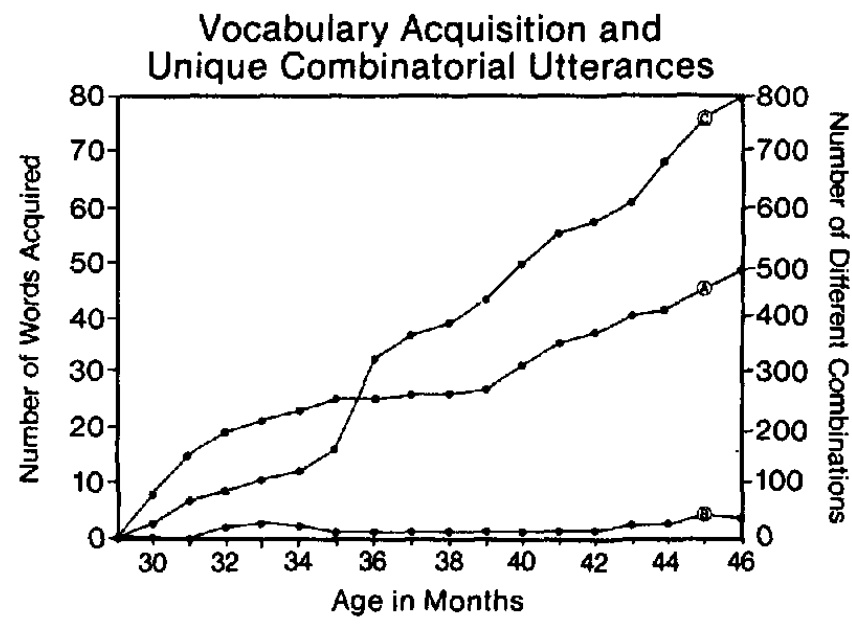

(A) Cumulative number of words meeting dual acquisition criterion. (Value on left $y$-axis)

(B) Cumulative number of words which drop below acquisition criterion after having met it. (Value on left $y$-axis)

(C) Cumulative number of unique non-imitated combinations. (Value on right $y$-axis)

Figure 1. Kanzi's acquisition of vocabulary items that met concordance criterion during the 17-month study period.

priate referents. Milk became confined to a specific referent, except from time to time, whenever Mulika appeared distracted and uncertain, she would still select milk and then proceed to gesturally clarify her intentions.

Kanzi, as well as Mulika, often began to use symbols within usage routines. In fact, most new symbols seem to appear in such routines for some time before they reach a stage of referential functioning. For example, the symbol for strawberries was introduced to Kanzi one day while he was eating mushrooms on mushroom trail. He was told that someone had learned of a place where strawberries could be found and everyone expressed excitement. Kanzi imitated the use of the symbol for strawberries and traveled with his companions. When they arrived, Kanzi readily consumed the strawberries. For a number of days thereafter, Kanzi's spontaneous usage of the symbol for strawberries occurred in, and only in, the context where it was first imitated, that is, while he was eating mushrooms at mushroom trail. It appeared that this activity would remind him of strawberries. He would then go to the keyboard, indicate "strawberries," and then indicate gesturally that he wanted to go and get them. Upon arrival though, he did not use the symbol to request or to name the strawberries, even if asked to do so. Later, he began to use the symbol to request strawberries once he arrived at the strawberries site. He also began to show that he comprehended utterances such as "hide strawberries", by running over and grabbing the strawberries before they could be hidden. It was only after his symbol usage and comprehension moved out of the initial acquisition routine that Kanzi could perform accurately on formal tests requiring him to select this symbol in response to the spoken English word.

This sort of associative usage is important and should be encouraged because it seems likely that many symbols are initially acquired in such routines, both by children and by apes (Lock, 1980). As a symbol's usage becomes expanded to an increasing number of contexts, it probably becomes more efficient to $a b-$ stract some commonalities from all of these different situations. It is these commonalities that then become the meaning of the symbol. For example, if Kanzi learns to touch the symbol for strawberries when he wants to travel to the place where they are found, when he is asking for one to eat, and when shown a photograph of strawberries, he will probably extract the one common referent (red sweet berries) from all of those different circumstances, and assign to that referent the symbol, strawberries. Once this happens, the symbol strawberries can be used to convey or to respond to information about strawberries apart from the routine(s) that were associated with the initial acquisition. Thus a novel combination, such as "hide strawberries" will be responded to correctly with searching behavior, once both the symbols hide and strawberries are no longer dependent for their interpretation or use upon the contexts of acquisition.

\section{Progress During the 17 Months After the Initial Separation From Matata}

Kanzi made rapid progress over the 17 months following his separation from Matata. Figure 1 illustrates Kanzi's single word acquisition from age 30 to 46 months based on the concordance measure. The specific symbols that met the criterion for vocabulary inclusion are shown in Table 1, broken down by months. Table 1 also reveals which symbols dropped out of the vocabulary after having initially met criterion.

Although Mulika began using symbols much earlier than Kanzi, her initial progress was considerably slower, suggesting again that Kanzi had learned many things that were not evident prior to the departure of his mother. Figure 2 shows Mulika's vocabulary acquisition between months 12 and 22, and Table 2 reveals the specific items that met criterion. Mulika's progress may be underestimated in both measures because people did not attempt to require her to display a behavioral concordance as frequently as they had Kanzi. Because formal testing was begun much earlier with Mulika, we tended to rely more heavily on these formal data to tell us which words Mulika had learned.

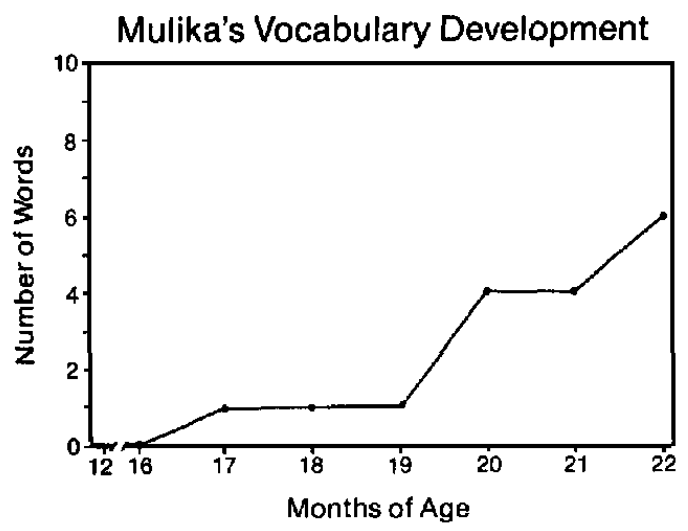

Figure 2. Number of words that have met concordance criterion for Mulika since her first word usuage until age 22 months. 
Table 1

Cumulative List of Kanzi's Symbol Acquisition

\begin{tabular}{|c|c|}
\hline Symbols & $\begin{array}{c}\text { Age acquired } \\
\text { (in months) }\end{array}$ \\
\hline $\begin{array}{l}\text { Orange } \\
\text { Peanut } \\
\text { Banana } \\
\text { Apple } \\
\text { Bedroom } \\
\text { Chase } \\
\text { Austin }\end{array}$ & 30 \\
\hline $\begin{array}{l}\text { Sweet potato } \\
\text { Raisin } \\
\text { Ball } \\
\text { Cherry } \\
\text { Peaches } \\
\text { Coke } \\
\text { 3ite }\end{array}$ & 31 \\
\hline $\begin{array}{l}\text { Melon } \\
\text { Jelly } \\
\text { Tomato } \\
\text { Orange drink }\end{array}$ & 32 \\
\hline $\begin{array}{l}\text { Trailer } \\
\text { Milk }\end{array}$ & 33 \\
\hline $\begin{array}{l}\text { Key } \\
\text { Tickle }^{\mathrm{c}}\end{array}$ & 34 \\
\hline $\begin{array}{l}\text { Coffee } \\
\text { Juice } \\
\text { Bread }\end{array}$ & 35 \\
\hline Groom & 37 \\
\hline Egg & 40 \\
\hline $\begin{array}{l}\text { Hamburger } \\
\text { Water } \\
\text { M \& M } \\
\text { Surprise }\end{array}$ & 41 \\
\hline $\begin{array}{l}\text { Clover } \\
\text { Matata } \\
\text { TV } \\
\text { Orange juice }\end{array}$ & 42 \\
\hline $\begin{array}{l}\text { Mulika } \\
\text { Carrot }\end{array}$ & 43 \\
\hline $\begin{array}{l}\text { Grab } \\
\text { Treehouse } \\
\text { Blanket } \\
\text { Blackberry }\end{array}$ & 44 \\
\hline Mushroom trail & 45 \\
\hline $\begin{array}{l}\text { Refrigerator } \\
\text { Hot dog }\end{array}$ & 46 \\
\hline
\end{tabular}

Note. Words with superscripts dropped below criterion for the month(s) indicated. " $33-46 .{ }^{\mathrm{b}} 32-34 .{ }^{\mathrm{c}} 44-45 .{ }^{\mathrm{d}} 43,45-46 .{ }^{\mathrm{e}} 45$.

When Mulika was asked to demonstrate concordance, she almost always did so correctly. During the last two thirds of the symbol-use period covered in the present report, concordances were requested of Mulika on 86 occasions, and she responded correctly to 85 of these requests. If a criterion of 10 or more consecutively correct spontaneous usages is used in place of the concordance criterion, Mulika's vocabulary rises to 37 words (milk, surprise, juice, bubbles, t-room, jelly, toothpaste, key, go, coke, blackberry, grape, staff office, jello, water, strawberry, cherry, sour cream, ice, banana, blueberry, orange drink, melon, coffee, kool-aid, M\&M, orange juice, orange, peanut, food, can opener, apple, peaches, bite, Matata, balloon, and lemonade)

As is the case with human children, Kanzi's symbol comprehension typically preceded his symbol production. Figure 3 contrasts the number of symbols acquired in the receptive mode with the number acquired in the productive mode. The criterion for acquisition in the receptive mode was 9 out of 10 correct behavioral responses when the symbol was used by a person. For example, someone might ask Kanzi to retrieve his ball from a group of objects, making certain not to gesture nor to glance toward the ball. Kanzi's receptive competency generally exceeded his productive competency; however, not all individual words met the receptive criterion prior to meeting the productive criterion. Overall, the receptive criterion was reached before the productive criterion for $63 \%$ of the words in Kanzi's vocabulary. However, the data in Figure 3 may underestimate the words that were learned first in the receptive mode, because special attempts to check for comprehension were not made regularly for words that had not yet met the vocabulary acquisition criterion. Comparable receptive data have not been compiled for Mulika; however, the formal test data described in later sections reveal that both her receptive and her labeling skills far exceed her productive vocabulary as defined by the concordance measure.

Spontaneous utterances consistently account for more than $80 \%$ of Kanzi's single-word and combinatorial utterances, as Figure 4 illustrates. Prompted, imitated, or partially imitated utterances accounted for only $11 \%$ of Kanzi's total corpus. Mulika's rate of spontaneous utterance production is slightly lower and her rate of imitated utterances somewhat higher (see Figure 5). Had Kanzi begun to use symbols earlier, he too might have gone through a period of greater reliance upon imitation as an acquisition strategy. It is also the case that when Kanzi was Mulika's age, there were only 8 symbols located on his mother's keyboard. Presently there are 256 symbols located on the board, hence Mulika is presented with a much more complex symbol array. The keyboard grew slowly larger as Kanzi's competence increased, whereas Mulika was presented with a complex keyboard from the onset of symbol acquisition.

Table 2

Cumulative List of Mulika's Symbol Acquistion

\begin{tabular}{lc}
\hline Symbols & $\begin{array}{c}\text { Age acquired } \\
\text { (in months) }\end{array}$ \\
\hline Milk & 17 \\
\hline $\begin{array}{l}\text { Key } \\
\text { T-room }\end{array}$ \\
Surprise & \\
\hline Juice & 20 \\
Water & 22 \\
\hline
\end{tabular}




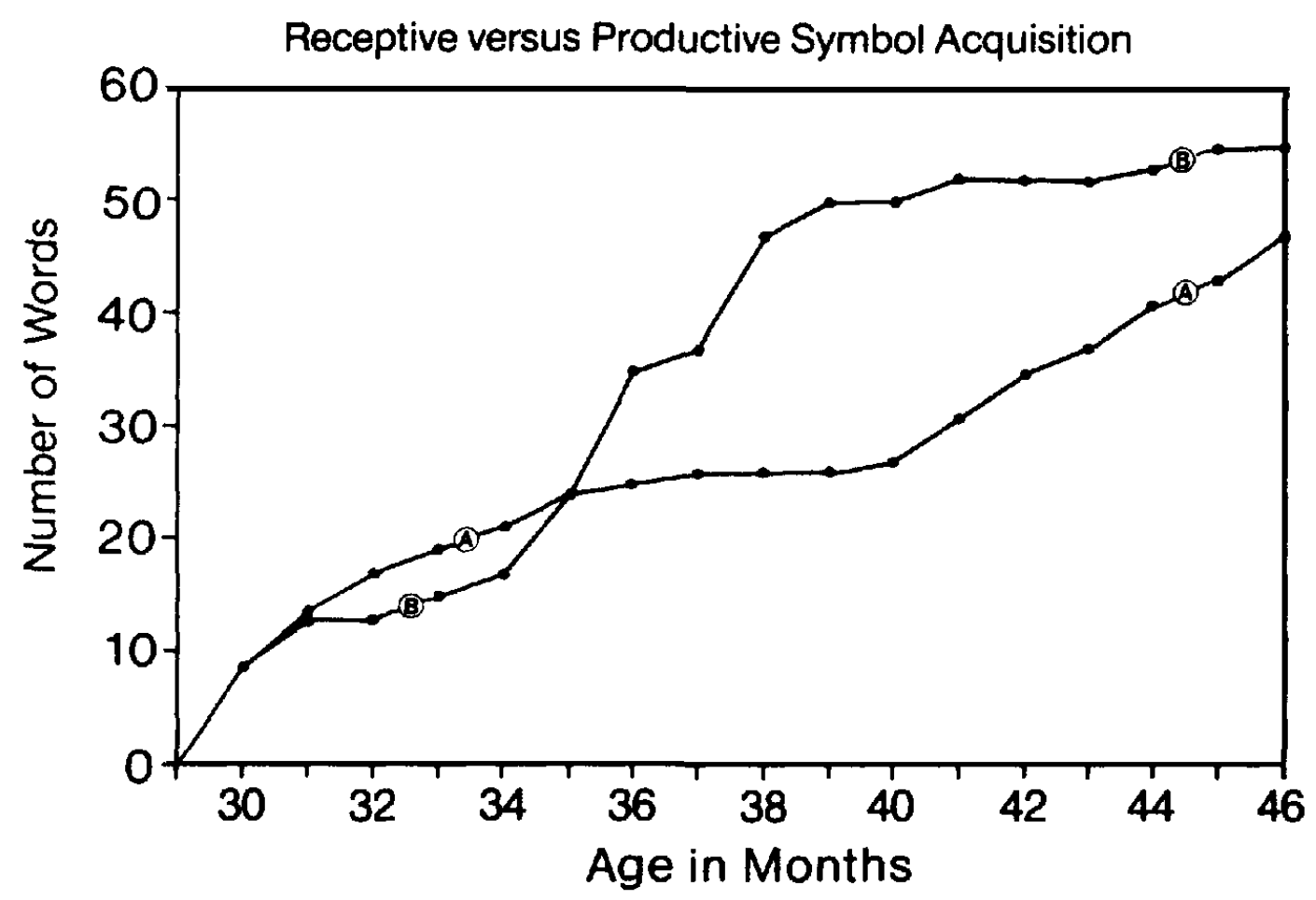

(A) Symbols That Meet Productive Criteria (B) Symbols That Meet Receptive Criteria

Figure 3. Kanzi's receptive and productive competency during the initial 17-month study period.

The data presented in Figures 4 and 5 illustrate that Kanzi and Mulika's symbol usage has been accurate the majority of the time. Although it is not feasible here to report every utterance that Kanzi and Mulika have produced, the Appendix gives a sample of their utterances for one randomly selected morning. (This day was selected from a month of data collected at the time of writing. None of the data were read prior to the selection, and the selection itself was made simply by shuffling the days, then taking one from the middle.) The Appendix also provides the context of each utterance. From this Appendix, the reader can gain an idea of the way that symbols are used across a variety of daily situations.

\section{Combinations}

Kanzi's multisymbol utterances, or combinations, appeared very early, within the first month of spontaneous keyboard usage. They were far less frequent than single symbol utterances throughout the 17-month period covered by this report. Across the first 17 months, Kanzi produced a total of 2,540 nonimitated combinations and 265 prompted or partially imitated. combinations. All but 10 of the nonimitated combinations were judged to be appropriate to the context and interpretable by his human companions. Of these 2,540 combinations, 764 were unique in that they occurred only once.

Kanzi's combinations accounted for only $6 \%$ of this total utterances during this period. Nevertheless, when Kanzi did use combinations, all of the symbols that he used typically added new elements of information to the situation. Thus, instead of forming combinations such as "play me Nim play" (Terrace, Petitto, Sanders, \& Bever, 1979), Kanzi produced combinations like "ice water go" (with "go" conveyed by gesture) to ask someone to get ice water for him.

Table 3 compares Kanzi's 25 most frequent two- and threeitem combinations with Nim's. Kanzi, unlike Nim, seems to provide additional information when he uses longer utterances. Yet the overall number of combinations produced by Kanzi $(2,540)$ during this period is small when contrasted with Nim, who produced approximately 19,000 combinations during a similar period of time. It does not appear that this large difference should be attributed to a greater loquaciousness on Nim's part because the majority of Nim's utterances seem to be redundant responses, solicited by repeated queries from his teachers.

Many of Kanzi's two-word utterances seem simply to be merged double-item requests, that is, requests for two distinct items that are uttered together. For example, on arriving at the food site where both hotdogs and coke were located, Kanzi often wanted to consume both foods and asked for them by indicating "hotdog coke." On other occasions he would use gestures to indicate that, in addition to wanting both foods, he wanted to have them mixed together.

The most interesting aspect of Kanzi's three-item utterances was that he used many of them to specify individuals other than 


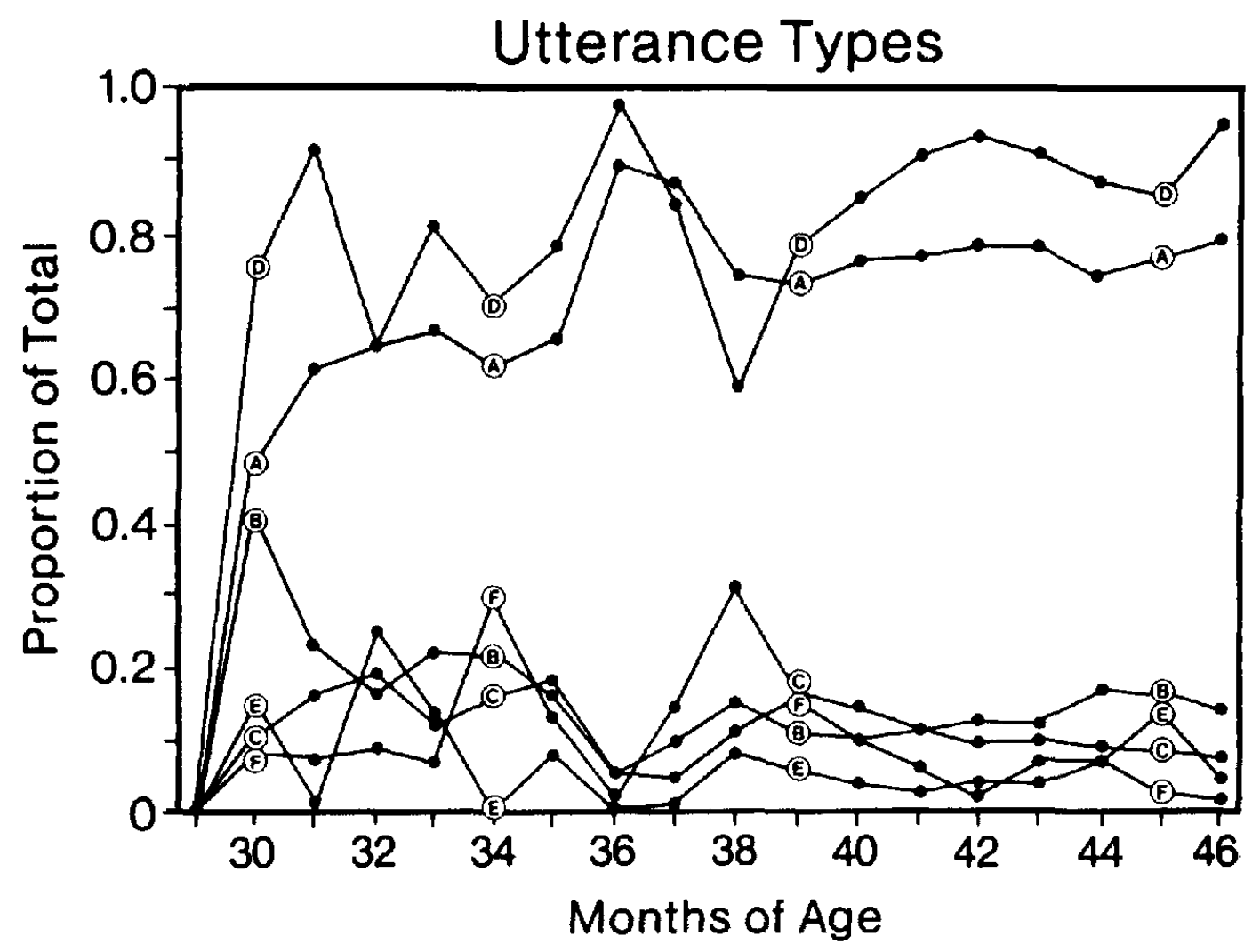

(A) Single words used spontaneously

(B) Single words elicited by companion's queries

(C) Single words used in imitation or as a result of prompting

(D) Combinations used spontaneously

(E) Combinations elicited bycompanion's queries

(F) Combinations used in imitation or as a result of prompting

Figure 4. Kanzi's utterance type categories for spontaneous, structured, and imitated usage.

himself as the agent or beneficiary of actions. Of Kanzi's threeword combinations, $36 \%$ were used to specify a beneficiary other than himself, whereas none of Nim's combinations functioned in this manner. It is also the case that $64 \%$ of Nim's most frequent two- and three-word combinations were food requests, whereas none of Kanzi's were. Thus the most frequent use of three-symbol utterances resulted from Kanzi's attempts to initiate games such as chase, grab, or tickle between various persons by indicating "grab" or "chase grab" at the keyboard and then taking one person's hand and pushing it toward the second person. In this way, he designated who was to be the agent or chaser and who was to be the recipient or chasee. These seemed to be deliberate choices on Kanzi's part and he would often reverse the agent-actor roles of such requests.
Requests that A chase B were Kanzi's own inventions, not imitations of people. The people who interacted with Kanzi did not play games of chase, grab, and bite with each other until Kanzi began to make his interest in observing these activities evident. It is interesting to note that until there is reason to specify an agent and a beneficiary other than onself, there is no need to make agent and beneficiary communicatively explicit. As long as the chimpanzee is to be the recipient of all food, tickling, trips outside, and so forth, there is no reason to specify himself as recipient nor the addressee as agent. Consequently, signs such as Nim, which Terrace has termed "wildcards," can be inserted into any combination without altering its meaning. By contrast, Kanzi needed to make the beneficiary and the agent explicit, because often, neither were himself. Clearly, prior to the emer- 


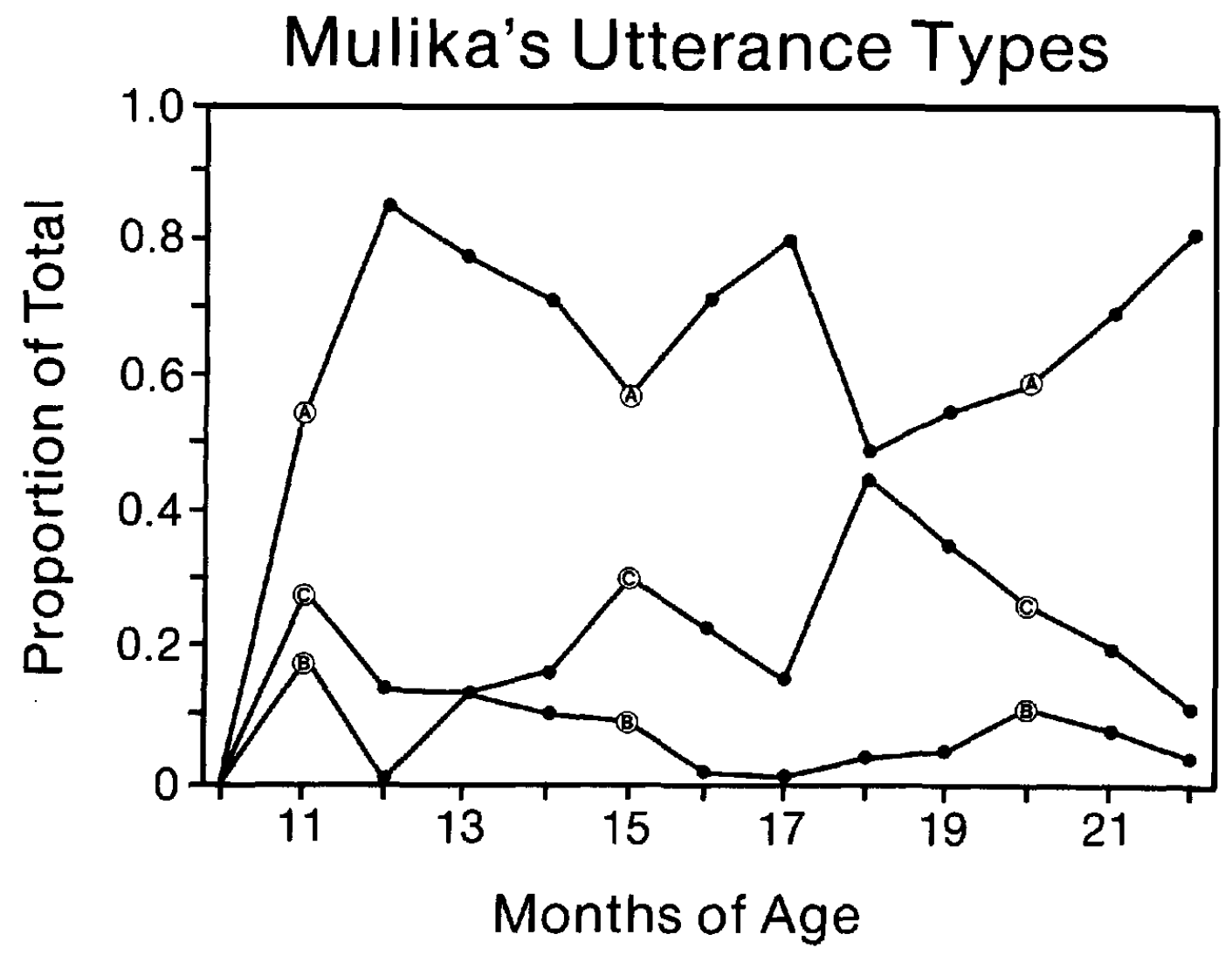

\section{(A) Single words used spontaneously \\ (B) Single words elicited by companion's queries \\ (C) Single words used in imitation or as a result of prompting}

Figure 5. Mulika's utterance type categories for spontaneous, structured, and imitated usage.

gence of syntax must be the emergence of the concept that one can request that $\mathrm{A}$ act on $\mathrm{B}$, where the speaker is neither $\mathrm{A}$ nor B.

\section{The Issue of Imitation}

It is informative to compare Kanzi's and Mulika's rates of imitated utterances with those of normal children, Nim (Sanders, 1985), and Sherman and Austin (see Table 4). Like human children, Kanzi and Mulika tend to imitate most often when they are learning new words. It seems reasonable to conclude that imitation is a strategy used by language learners when they are not sure what to say in a given situation. Moreover, if the language model realizes this, the model will typically show them what to say, thereby setting the stage for imitation to occur.

Table 4 also contrasts the proportion of Kanzi's and Mulika's utterances that were spontaneous with those of Sherman, Austin, and Nim (Sanders, 1985). Clearly, a large proportion of
Kanzi's and Mulika's utterances were truly spontaneous and were not elicited by the teacher creating situations that required an utterance. This means that, most of the time, they are adding new information to the situation, as opposed to simply saying what is expected of them in order to achieve "a way out." The majority of Sherman's and Austin's utterances were spontaneous in the sense that the teacher did not emit a preceding utterance or query, however, the teacher did generally do something to precipitate an utterance, such as place food in a tool site during the training or practice of tool names. Consequently, even though they frequently produced spontaneous utterances, such utterances were more closely linked to situations promoted by specific actions on the part of their teachers than was the case for Kanzi and Mulika.

\section{Formal Tests}

Formal tests required a very different sort of symbol orientation than Kanzi and Mulika normally encountered in their day- 
Table 3

Comparison of Most Frequent Combinations

\begin{tabular}{ll}
\multicolumn{1}{c}{ Kanzi } & \multicolumn{1}{c}{ Nim } \\
\hline & 2 items \\
Chase person(g) & \\
Person(g) chase(g) & Play me \\
Chase(g) Person(g) & Me Nim \\
Person(g) pat(g) & Ticle me \\
Chase bite & Eat Nim \\
Chase Kanzi & More eat \\
Person(g) come(g) & Me eat \\
Tickle ball & Nim eat \\
Bite person(g) & Finish hug \\
Come(g) chase(g) & Drink Nim \\
Ball tickle & More tickle \\
Chase Sue & Sorry hug \\
Kanzi chase & Tickle Nim \\
Surprise money & Hug Nim \\
Bite chase & More drink \\
Pat(g) person(g) & Eat drink \\
Kanzi grab & Banana me \\
Grab person(g) & Nim me \\
Chase bite & Sweet Nim \\
Pat(g) this(g) & Me play \\
Chase come(g) & Gum eat \\
Person(g) go(g) & Tea drink \\
Ball pat(g) & Grape eat \\
Person(g) bite & Hug me \\
Chase tickle & Banana Him \\
& In pants \\
& \\
&
\end{tabular}

3 items

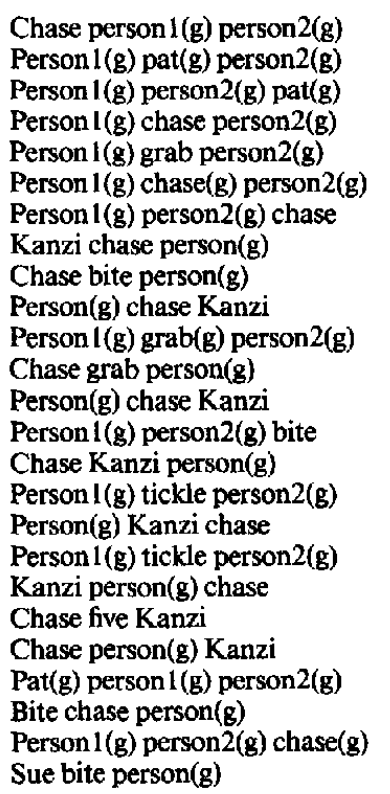

Play me Nim

Eat me Nim

Eat Nim eat

Tickle me Nim

Grape eat Nim

Banana Nim eat

Nim me eat

Banana eat Nim

Eat me eat

Me Nim eat

Hug me Nim

Yogurt Nim eat

Me more eat

More eat Nim

Finish hug Nim

Banana me eat

Nim eat Nim

Tickle me tickle

Apple me eat

Eat Nim me

Give me eat

Nut Nim nut

Drink me Nim

Hug me hug

Sweet Nim sweet

Note. A (g) after a word means that it was a gesture, not a lexigram.

to-day activities because such tests are, by their very nature, noncommunicative. Thus, instead of touching "juice" because they wanted to travel to a location in the woods where juice was found, formal tests required Kanzi and Mulika to select juice because someone held up a photograph and asked them what it was. Touching the symbol for juice in this context did not result in anything different or significant happening, as was the case when juice was used in a communicative context.

In spite of these differences, Kanzi and Mulika did well on formal tests from their first administration. They seemed to understand that the experimenters were not communicating about something that was going to happen as they touched a symbol, but rather were posing a specific question. Sherman and Austin, by contrast, when first asked to label items in a test, appeared to anticipate that they would receive the item as a consequence of touching the symbol. When they did not, they became confused and consequently, labeling had to be introduced slowly (Savage-Rumbaugh, 1986). Kanzi's and Mulika's abilities to select lexigrams in response to the spoken English word, to select photographs in response to the spoken English word, and to select photographs when shown lexigrams, are depicted according to the type of test and the vocabulary items in Tables 5 and 6. Clearly, these tests confirmed that Kanzi and Mulika had associated various referents with lexigrams, that these associations were bidirectional, and that spoken English words were as closely linked to lexigrams as were the items that the lexigrams represented.

At the time these tests were given to Mulika, it was thought that she knew only a few lexigrams well enough to accurately select them out of context in a formal test. However, her test results quickly revealed that her capacities had been underestimated and illustrated that she knew 42 symbols, a number of which she had not yet used herself.

Similar tests were given to Sherman and Austin, although some of the vocabulary items differed because the words they were taught were not, in many cases, identical to those that Kanzi acquired. Sherman and Austin were able to select the correct photograph when shown the lexigram; however, their performance dropped to chance when they were asked to select the correct photograph in response to a spoken English word (see Table 7). Not only were Sherman and Austin unable to select the correct item when the sample was the English word, but they also seemed not to like these trials and attempted to avoid them by requesting to go elsewhere; and at times, they refused to respond. Both Sherman and Austin repeatedly scratched themselves over their entire bodies (a behavior that signals frustration in chimpanzees) during English trials, but not at all during lexigram trials. Unexpectedly, Sherman and Austin vocalized frequently during the English trials, either to initiate a trial

Table 4

Imitated Versus Spontaneous Utterances

\begin{tabular}{lcc}
\hline Subject & $\begin{array}{c}\text { Proportion of } \\
\text { imitated utterances }\end{array}$ & $\begin{array}{c}\text { Proportion of } \\
\text { spontaneous utterances }\end{array}$ \\
\hline Kanzi & .11 & .80 \\
Mulika & .20 & .67 \\
Nim & .39 & .56 \\
Sherman & .10 & .78 \\
Austin & .05 & .90 \\
Stage I child & .18 & .82 \\
\hline
\end{tabular}

Note. Data for the Stage 1 child were taken from Bloom, Hood, and Lightbown (1974) and reflect a combination of their categories of incidental and nonincidental speech. 
Table 5

Vocabulary Test: Kanzi

\begin{tabular}{|c|c|c|c|c|}
\hline Item & $\begin{array}{l}\text { Match } \\
\text { symbol to } \\
\text { English }\end{array}$ & $\begin{array}{l}\text { Match } \\
\text { photo to } \\
\text { English }\end{array}$ & $\begin{array}{l}\text { Match } \\
\text { photo to } \\
\text { symbol }\end{array}$ & $\begin{array}{c}\text { Match } \\
\text { symbol to } \\
\text { Votrax speech }\end{array}$ \\
\hline A-frame & $\mathbf{X}$ & C & C & C \\
\hline Apple & $\mathrm{C}$ & C & $\mathrm{C}$ & C \\
\hline Austin & $\mathrm{C}$ & C & $\mathrm{C}$ & $\mathrm{C}$ \\
\hline Ball & $\mathrm{C}$ & C & $\mathrm{C}$ & C \\
\hline Banana & $\mathrm{C}$ & $\mathrm{C}$ & C & $\mathrm{C}$ \\
\hline Blackberry & C & $\mathrm{C}$ & $\mathrm{C}$ & $\mathrm{C}$ \\
\hline Blanket & $\mathrm{C}$ & C & $\mathrm{C}$ & $\mathrm{C}$ \\
\hline Bread & C & C & $\mathrm{C}$ & C \\
\hline Campfire & C & $\mathrm{C}$ & $\mathrm{C}$ & $\mathrm{C}$ \\
\hline Carrot & $\mathrm{C}$ & C & $\mathrm{C}$ & $\mathrm{C}$ \\
\hline Chase & $\mathrm{C}$ & NP & NP & $\mathrm{C}$ \\
\hline Cherries & C & $\mathrm{X}$ & C & $\mathrm{C}$ \\
\hline Cheese & $\mathrm{C}$ & $\mathrm{C}$ & $\mathrm{C}$ & $\mathrm{C}$ \\
\hline Childside & C & C & $\mathbf{X}$ & $\mathrm{C}$ \\
\hline Chow & $\mathrm{C}$ & $\mathbf{X}$ & $X$ & $\mathrm{C}$ \\
\hline Clover & $\mathrm{C}$ & C & $\mathrm{C}$ & $\mathrm{C}$ \\
\hline Coffee & C & $\mathrm{C}$ & C & $\mathrm{C}$ \\
\hline Coke & $\mathrm{C}$ & $\mathrm{C}$ & $\mathrm{C}$ & $\mathrm{C}$ \\
\hline Colony room & $\mathrm{C}$ & $\mathrm{C}$ & $\mathrm{C}$ & $\mathrm{C}$ \\
\hline Dig & $\mathrm{C}$ & NP & NP & $\mathbf{X}$ \\
\hline Dog & $\mathrm{C}$ & $\mathrm{C}$ & $\mathrm{C}$ & $\mathbf{X}$ \\
\hline Flashlight & C & $\mathrm{C}$ & $\mathrm{C}$ & $\mathbf{X}$ \\
\hline Egg & $\mathrm{C}$ & $\mathrm{C}$ & $\mathrm{C}$ & $\mathrm{C}$ \\
\hline Grab & $\mathrm{C}$ & NP & NP & $\mathrm{C}$ \\
\hline Grean bean & C & $\mathrm{C}$ & C & $\mathrm{C}$ \\
\hline Groom & C & $\mathrm{C}$ & $\mathrm{C}$ & $\mathrm{C}$ \\
\hline Group room & C & C & $\mathrm{X}$ & $\mathrm{X}$ \\
\hline Hamburger & C & C & $\mathrm{C}$ & $\mathrm{C}$ \\
\hline Hotdog & $\mathrm{C}$ & $\mathrm{C}$ & $\mathrm{C}$ & $\mathrm{C}$ \\
\hline Ice & $\mathrm{C}$ & $\mathrm{C}$ & C & $\mathrm{C}$ \\
\hline Jelly & $\mathrm{C}$ & $\mathrm{C}$ & $\mathrm{C}$ & $\mathrm{C}$ \\
\hline Juice & C & $\mathrm{C}$ & C & $\mathrm{C}$ \\
\hline Keys & C & $\mathrm{C}$ & C & C \\
\hline M\&M & $\mathrm{C}$ & $\mathrm{C}$ & $\mathrm{C}$ & $\mathrm{C}$ \\
\hline Matata & $\mathrm{C}$ & $\mathrm{C}$ & $\mathrm{C}$ & $\mathrm{C}$ \\
\hline Melon & $\mathrm{C}$ & $\mathrm{C}$ & $\mathrm{C}$ & C \\
\hline Milk & $\mathrm{C}$ & $\mathrm{C}$ & C & $\mathrm{C}$ \\
\hline Mulika & $\mathrm{C}$ & $\mathrm{C}$ & C & $\mathbf{X}$ \\
\hline Mushroom & $\mathrm{C}$ & $\mathrm{C}$ & $\mathrm{C}$ & C \\
\hline Open & C & NP & NP & $\mathrm{X}$ \\
\hline Orange & C & $\mathrm{C}$ & $\mathrm{C}$ & $\mathrm{C}$ \\
\hline Orange juice & $\mathrm{C}$ & $\mathrm{C}$ & C & $\mathrm{C}$ \\
\hline Orange drink & C & $\mathbf{X}$ & $\mathbf{X}$ & $\mathrm{C}$ \\
\hline Outdoors & $\mathrm{C}$ & C & $\mathrm{C}$ & C \\
\hline Peanut & $\mathrm{C}$ & C & C & C \\
\hline Peaches & $\mathrm{C}$ & C & $\mathrm{C}$ & $\mathrm{C}$ \\
\hline Pine cone & $\mathrm{C}$ & C & C & $\mathbf{X}$ \\
\hline Play yard & $\mathrm{C}$ & $\mathrm{C}$ & $\mathrm{C}$ & C \\
\hline Raisin & C & C & $\mathrm{C}$ & $\mathrm{C}$ \\
\hline Refrigerator & C & C & $\mathrm{C}$ & C \\
\hline Rubber band & $\mathrm{C}$ & $\mathrm{C}$ & $\mathrm{C}$ & $\mathrm{X}$ \\
\hline Scrubby pine & $\mathrm{C}$ & NP & NP & $X$ \\
\hline Sherman & $\mathrm{C}$ & $\mathrm{C}$ & C & $\mathrm{X}$ \\
\hline Sour cream & $\mathrm{C}$ & $\mathrm{C}$ & $\mathrm{C}$ & $\mathrm{X}$ \\
\hline Staff office & $\mathrm{C}$ & NP & NP & C \\
\hline Sue's office & $\mathrm{C}$ & $\mathrm{C}$ & C & $\mathrm{C}$ \\
\hline Surprise & $\mathrm{C}$ & NP & NP & C \\
\hline Sweet potato & C & C & C & $\mathbf{X}$ \\
\hline TV & C & $\mathrm{C}$ & C & $\mathrm{C}$ \\
\hline Tickle & $\mathrm{C}$ & $\mathrm{C}$ & C & $\mathrm{C}$ \\
\hline Tomato & C & $\mathrm{C}$ & $\mathrm{C}$ & $\mathrm{C}$ \\
\hline Trailer & $\mathrm{C}$ & $\mathrm{C}$ & C & C \\
\hline Treehouse & $\mathrm{C}$ & $\mathrm{C}$ & $\mathrm{C}$ & $\mathrm{X}$ \\
\hline Turtle & C & $\mathrm{C}$ & $\mathrm{C}$ & $\mathrm{X}$ \\
\hline Umbrella & $\mathrm{C}$ & C & $\mathrm{C}$ & $\mathrm{C}$ \\
\hline Water & C & C & $\mathrm{C}$ & $\mathbf{X}$ \\
\hline
\end{tabular}

Note. $\mathrm{C}=$ correct response on 3 of 3 test trials. $\mathrm{X}=$ incorrect response on 2 or 3 of 3 test trials. NP $=$ not presented due to lack of good photograph. or when they were to select a photograph. They did not vocalize during the lexigram trials. The vocalization they used was a sound that is not part of the Pan troglodytes' repertoire, but one that they learned to make during previous attempts to imitate people (Savage-Rumbaugh, 1986).

In order to rule out the possibility that Kanzi's ability to respond to spoken English was based on some nonphonemic aspect of speech (such as the rhythm or intonation pattern of speech) the English word comprehension test was readministered using a Votrax speech synthesizer. Each symbol was presented three times during this test and was paired with two different alternatives on each presentation. Speech produced by the synthesizer is often difficult for individuals unaccustomed to it to interpret. Also, words vary in their clarity, with some being more interpretable than others. Kanzi's accuracy with synthesized speech was slightly lower than with normal speech; however, his difficulties were not global, but linked to particular words. The authors experienced difficulties understanding many of the same words.

\section{Announcement and Verification of Travel Plans}

When traveling long distances (over $20 \mathrm{~m}$ ) Kanzi typically rode on a person's shoulders and extended his hand to indicate which way to go. If the person did not respond, he would turn their head in the appropriate direction. As he became older, he was encouraged to walk greater distances. Kanzi learned the location of 17 different food sites within 4 months after they were introduced. He seemed to understand within a few days that the photographs (recall that several photographs were typically laid out from which Kanzi was to indicate/choose a destination) served as a means of communicating to the people where he would like to go, and at times he would go out of the way to make certain that the person had seen the photograph that he had selected.

During a blind test of Kanzi's knowledge of the foraging sites, he selected a photograph on five occasions and a lexigram on seven occasions; both a photograph and a symbol were chosen on three additional occasions. Each time he then led the experimenter to the correct location, sometimes traveling over $30 \mathrm{~min}$ to reach the previously selected destination. En route, Kanzi often pointed to the photograph or to the symbol, as though to remind himself and the experimenter where they were headed. Figure 6 shows the area Kanzi covered and the location of each food. Kanzi's path can be retraced by following the numbers at each site (i.e., Site 1 is the first site Kanzi visited, Site 2 is the second site, etc.). As Kanzi traveled from one place to another, many opportunities arose for him to take a wrong turn and to thus go somewhere else other than the destination that he had indicated. Table 8 gives the minimum number of trail selections that could have been made before arriving at the correct destination, and the number of turns Kanzi actually made. On all but one trial, Kanzi took the most direct route possible. In the single instance that he did not, he directed the blind experimenter to take him to the back of the 55 acres, an area where he is not normally allowed to go. As seen in Figure 6, he directed the experimenter to the very end of the enclosure before returning. Presumably, Kanzi took advantage of the blind experimenter's naivete to go places that he did not normally get to travel. 
Table 6

Vocabulary Test: Mulika

\begin{tabular}{|c|c|c|c|}
\hline Item & $\begin{array}{l}\text { Match } \\
\text { symbol to } \\
\text { English }\end{array}$ & $\begin{array}{l}\text { Match } \\
\text { photo to } \\
\text { English }\end{array}$ & $\begin{array}{l}\text { Match } \\
\text { photo to } \\
\text { symbol }\end{array}$ \\
\hline Apple & C & C & C \\
\hline Ball & $\mathrm{C}$ & C & $\mathrm{C}$ \\
\hline Blackberry & $\mathrm{C}$ & $\mathrm{C}$ & $\mathrm{C}$ \\
\hline Blueberry & C & $\mathrm{C}$ & $C$ \\
\hline Bubbles & $\mathrm{C}$ & $\mathrm{C}$ & $\mathrm{C}$ \\
\hline Bunny & $\mathrm{C}$ & $\mathrm{C}$ & C \\
\hline Cereal & C & C & $\mathrm{C}$ \\
\hline Cherry & C & $\mathrm{C}$ & C \\
\hline Clover & $\mathrm{C}$ & C & $\mathrm{C}$ \\
\hline Canopener & C & C & $\mathrm{C}$ \\
\hline Coffee & C & $\mathrm{C}$ & $\mathrm{C}$ \\
\hline Coke & $\mathrm{C}$ & $\mathrm{C}$ & $\mathrm{C}$ \\
\hline Egg & C & $\mathrm{C}$ & $\mathrm{C}$ \\
\hline Campfire & $\mathrm{C}$ & C & $\mathrm{C}$ \\
\hline Food & $\mathbf{X}$ & C & $\mathrm{C}$ \\
\hline Grape & C & C & C \\
\hline Hamburger & C & $\mathrm{C}$ & $\mathrm{C}$ \\
\hline Hotdog & $\mathrm{C}$ & $\mathrm{X}$ & $C$ \\
\hline Ice & $\mathrm{C}$ & $\mathrm{C}$ & $\mathrm{C}$ \\
\hline Juice & C & C & $\mathrm{C}$ \\
\hline Key & $\mathrm{C}$ & $\mathrm{C}$ & C \\
\hline Lemonade & C & C & $\mathrm{C}$ \\
\hline Matata & C & C & C \\
\hline Milk & $\mathrm{C}$ & $\mathrm{C}$ & C \\
\hline Melon & $\mathrm{C}$ & $\mathrm{C}$ & C \\
\hline Outdoors & $\mathrm{C}$ & NP & C \\
\hline Pine needle & C & C & C \\
\hline Orange drink & C & C & C \\
\hline Orange juice & C & C & $\mathrm{C}$ \\
\hline Onion & $\mathrm{C}$ & $\mathbf{X}$ & $\mathrm{C}$ \\
\hline Peas & C & $\mathrm{C}$ & C \\
\hline Peanut & $\mathrm{C}$ & $\mathrm{C}$ & C \\
\hline Raisin & C & C & $\mathrm{C}$ \\
\hline Rock & C & C & $\mathrm{C}$ \\
\hline Rubberband & C & $\mathbf{X}$ & $\mathbf{X}$ \\
\hline Sweet potato & C & C & $\mathrm{C}$ \\
\hline Potato & C & $\mathbf{X}$ & C \\
\hline Sour cream & C & $\mathbf{X}$ & $\mathrm{C}$ \\
\hline Surprise & C & C & $\mathrm{C}$ \\
\hline Strawberry & C & C & C \\
\hline Tomato & C & C & C \\
\hline Toothpaste & C & C & C \\
\hline
\end{tabular}

Note. $\mathrm{C}=$ correct response on 3 of 3 test trials. $\mathrm{X}=$ incorrect response on 2 or 3 of 3 test trials. NP $=$ not presented due to lack of good photograph.

This out-of-the-way side trip lasted $30 \mathrm{~min}$ and took the experimenter off the trails and through some of the densest brush possible. After exploring this area, Kanzi led the experimenter back to the trail and on the correct location.

Kanzi did not suggest traveling to two places in the field during this test. Consequently, when Kanzi no longer appeared to want to initiate travel, the experimenter used spoken English to ask that Kanzi lead her to the two remaining unvisited locations. Kanzi obliged, again taking the most direct possible route. Kanzi's ability to announce his desire to travel to a particular location, and then to lead someone there, cannot be attributed to a set travel plan or to a routine, because his travel patterns varied considerably from day to day as seen in Table 9.
This test was not given to Mulika, because at the time of writing, she was not comfortable traveling in the woods without Kanzi along; in addition, Kanzi generally insisted on leading the way.

\section{General Observations Regarding Kanzi and Mulika's Symbol Usage}

Kanzi seems able to generalize beyond the typical referent of a given symbol, as have other apes (Gardner \& Gardner, 1984). He has, for example, used coke to refer to all brands of dark carbonated drinks, rain to refer to the sprinkling produced from the spray of a hose, tomato to refer to a variety of small, round red fruits (e.g., strawberries and cherries), and bread to refer to all varieties of bread, including taco shells. Kanzi has used hamburger to refer to all cuts of beef, raw or cooked, hide to refer to hiding, finding, and exploring new areas of forest, and chase to refer to following, as well as to games of tag. Some symbols are used for a number of different referents that are similar along a common dimension, even though prior to Kanzi's use of the word for such referents, the dimension of similarity was not recognized by the people. For example, Kanzi has used clover to refer to the specific plant, but he also uses it to refer to parsley that grows in tight clusters on the

Table 7

Vocabulary Test: Sherman and Austin

\begin{tabular}{|c|c|c|c|c|}
\hline \multirow[b]{2}{*}{ Item } & \multicolumn{2}{|c|}{$\begin{array}{l}\text { Match photo } \\
\text { to English }\end{array}$} & \multicolumn{2}{|c|}{$\begin{array}{l}\text { Match photo } \\
\text { to symbol }\end{array}$} \\
\hline & Sherman & Austin & Sherman & Austin \\
\hline Banana & $\mathbf{X}$ & $\mathbf{X}$ & C & C \\
\hline Blanket & $\mathbf{X}$ & $\mathbf{X}$ & $\mathrm{C}$ & C \\
\hline Beancake & $\mathrm{X}$ & $\mathrm{X}$ & C & C \\
\hline Bread & $\mathbf{X}$ & $\mathbf{X}$ & C & C \\
\hline Cake & $\mathbf{X}$ & $\mathbf{X}$ & C & C \\
\hline Carrot & $\mathrm{X}$ & $\mathbf{X}$ & C & C \\
\hline Cheese & $\mathbf{X}$ & $\mathbf{X}$ & C & C \\
\hline Cherry & $\mathrm{X}$ & $\mathbf{X}$ & C & C \\
\hline Chow & $\mathrm{X}$ & $\mathbf{X}$ & $\mathrm{C}$ & C \\
\hline Coke & $\mathbf{X}$ & C & $\mathrm{C}$ & C \\
\hline Collar & $\mathbf{X}$ & $\mathbf{X}$ & C & C \\
\hline Corn & $\mathbf{X}$ & $\mathbf{X}$ & C & C \\
\hline Jelly & $\mathbf{X}$ & $\mathrm{X}$ & $\mathrm{C}$ & C \\
\hline Juice & $\mathbf{X}$ & $\mathbf{X}$ & $\mathrm{C}$ & $\mathrm{C}$ \\
\hline Key & C & C & $\mathrm{C}$ & C \\
\hline Magnet & $\mathbf{X}$ & $\mathrm{X}$ & C & $\mathrm{C}$ \\
\hline Melon & $\mathrm{X}$ & $\mathbf{X}$ & C & C \\
\hline Money & $\mathbf{X}$ & $\mathrm{X}$ & C & $\mathrm{C}$ \\
\hline Orange drink & $\mathbf{X}$ & $\mathbf{X}$ & C & C \\
\hline Outdoors & C & C & C & C \\
\hline Peaches & $\mathbf{X}$ & $\mathbf{X}$ & C & $\mathrm{C}$ \\
\hline Peanut & $\mathbf{X}$ & $\mathbf{X}$ & C & C \\
\hline Pudding & $\mathrm{X}$ & $\mathbf{X}$ & $\mathrm{C}$ & C \\
\hline Raisin & $\mathbf{X}$ & $\mathbf{X}$ & C & $\mathrm{C}$ \\
\hline Shot & $\mathbf{X}$ & $\mathbf{X}$ & $C$ & C \\
\hline Sponge & $\mathbf{X}$ & $\mathrm{X}$ & $\mathrm{C}$ & C \\
\hline Stick & $\mathrm{X}$ & $\mathbf{x}$ & C & C \\
\hline Straw & $\mathbf{X}$ & $\mathbf{X}$ & C & C \\
\hline Tomato & $\mathbf{X}$ & $\mathbf{X}$ & C & $\mathrm{C}$ \\
\hline Wrench & $\mathbf{X}$ & $\mathbf{X}$ & C & C \\
\hline
\end{tabular}

Note. $\mathrm{C}=$ correct response on 3 of 3 test trials. $\mathrm{X}=$ incorrect response on 2 or 3 of 3 test trials. 


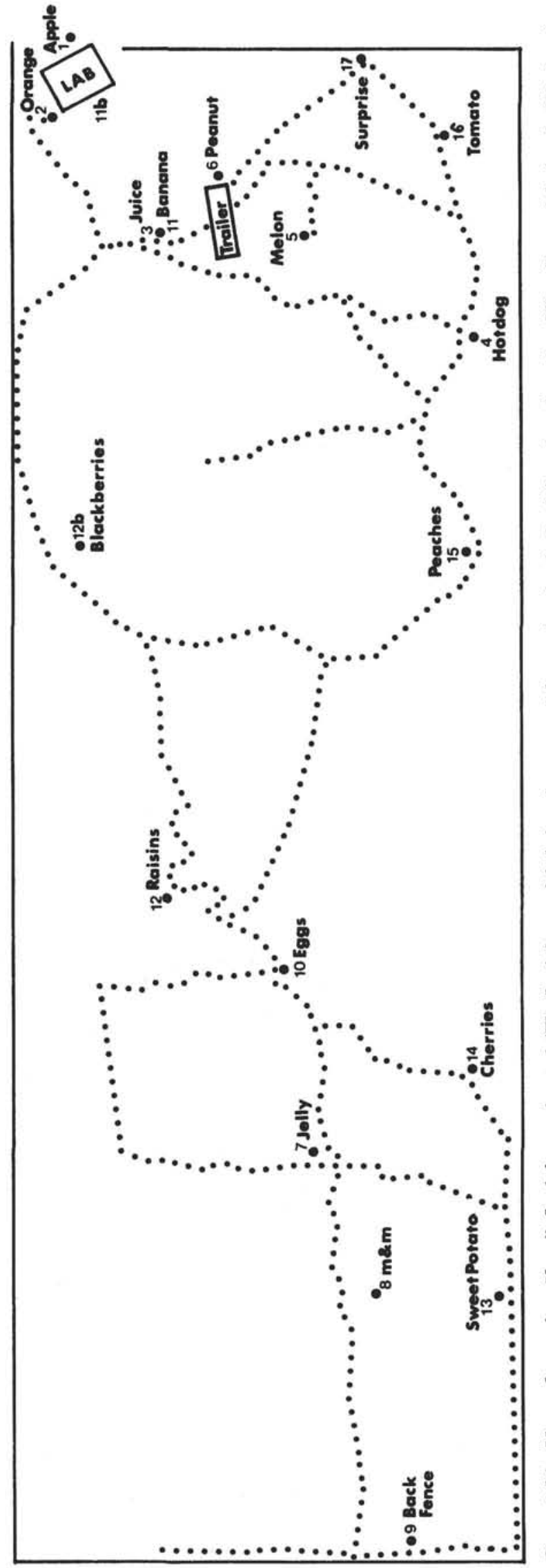

ground and to red bud blossoms that grow in tight cloverlike clusters on a tree. By contrast, other terms applying to outdoor vegetation, such as pine needles and velvet plant have been used only for these specific plants. Similarly, Mulika has used apple to refer to plums, paint to refer to crayons, and peas to refer to green beans.

Kanzi is also able to use symbols in different ways depending upon the context. For example, because many of the foods are located in the woods, he often uses a food name, such as juice, to indicate that he wants to go to the location (treehouse) where juice is typically found. Upon arriving there, he may show no interest in the juice but instead play in the trees, on the ropes, and in the treehouse located at this particular area. Yet, even while Kanzi is playing, if he is asked to select the juice from a group of foods, he will do so. And if a bottle of juice is held up and he is asked to name it, he will do so readily and then continue playing.

On many occasions, Kanzi asks to travel from one location to another without ever eating the food at the current location, even though he initially used the food name as a means of specifying that location. Thus, the food name is extended to serve as a general place name, when uttered in the context of traveling through the woods. (Kanzi's models, typically, though not invariably, use the location term when they specify where they intend to go and Kanzi comprehends many of those terms, as evidenced by his ability to lead people to a specific location, such as the treehouse, upon request. However, if asked en route where he is going, the likely answer is "juice".)

When particular foods are not associated with particular locations, Kanzi has nonetheless learned to use the location name. However, the area of space to which he applies the symbol often seems to be much broader than the area to which the people refer. For example, Kanzi's use of Sue's office refers not only to the indoor area of this office, but also to a large area outdoors that is around the office. Similarly, play yard is a term used by the people to refer to the outdoor caging area occupied by Matata. Kanzi has used this term to refer to the entire grassy area behind the lab, and as a means of requesting both to go into, and out of, Matata's outdoor cage. Also, if Kanzi is out in the woods, a long distance from the lab, he may use a number of words such as Sue's office, bedroom, or childside to indicate that he wishes to travel back toward the lab. Upon arriving at the lab, however, Kanzi will then specify a particular part of the lab that he did not mention while out in the woods. It is as though the farther he is from the lab, the more general is the referent of the location terms that are used. However, once he is within the lab, he then uses the terms with greater specificity.

Kanzi frequently takes the keyboard and goes off by himself to use it. He seems to be practicing in such circumstances. He has, for example, pointed to a lexigram such as pine needle, and then gathered together a pile of pine needles. He has touched the symbol rock and then piled tiny pebbles on top of the rock lexigram. He often points to hide and then covers himself with the keyboard or with blankets. When experimenters attempt to interact with him during such activities, he abruptly terminates the interaction and departs, as though such things are not meant to be social activities. Similar behavior has not yet been observed in Mulika.

Kanzi also has used the keyboard to express a willingness to 
Table 8

Leading Person to Preselected Location: Blind Test

\begin{tabular}{|c|c|c|}
\hline Site selected & $\begin{array}{l}\text { Minimum possible } \\
\text { selections }\end{array}$ & $\begin{array}{c}\text { Number of } \\
\text { selections made }\end{array}$ \\
\hline Apple & 1 & 1 \\
\hline Orange & 1 & 1 \\
\hline Juice & 2 & 2 \\
\hline Hotdog & 2 & 2 \\
\hline Melon & 3 & 3 \\
\hline Peanut & 2 & 2 \\
\hline Jelly & 7 & 7 \\
\hline M\&M & 2 & 2 \\
\hline Egg & 3 & 4 \\
\hline Back fence $\mathrm{a}^{\mathrm{a}}$ & NA & NA \\
\hline Banana & 7 & 7 \\
\hline Raisin $^{6}$ & 4 & 4 \\
\hline Blackberry & 1 & 1 \\
\hline Sweet potato & 4 & 4 \\
\hline Cherry & 2 & 2 \\
\hline Peaches & 6 & 6 \\
\hline Tomato & 4 & 4 \\
\hline Surprise & 1 & 1 \\
\hline
\end{tabular}

Note. Whenever the minimum number of selections equal the number of selections made by Kanzi, it indicates that he took the most direct route. If the numbers are not equal, Kanzi took a longer route but still arrived at the correct location.

"The back fence was not a location used in the test, hence data on the route is not applicable (NA).

b The second day of testing began here and raisin was reached by starting from the lab. En route to raisins, Kanzi asked to go to blackberries, which were on the way. After eating blackberries, he selected raisins once again and led the way.

behave differently. On occasion, if he is taken inside when he does not want to go he will respond "no colony" or "no play yard" to indicate that he does not want to be where he is. Once, when he was disciplined by being confined indoors for repeatedly eating wild mushrooms, Kanzi emphatically touched "no bite mushrooms." When queried as to whether he would be "good outdoors," he responded with positive vocalizations and then behaved appropriately when allowed to go back outdoors.

\section{Discussion}

It is important to note that the data in the present report were compiled from the daily notes and reflect all of Kanzi's and Mulika's utterances during the period covered in this report. Previous ape language reports generally have not presented data that summarize all utterances across a significant length of time. Similarly, previous reports have not scored utterances with regard to accuracy given the context, and receptive responses have not been recorded at all. This is the first body of evidence accumulated for apes that documents and evaluates the entire corpus of symbol usage and comprehension.

Previous studies also have been criticized for presenting anecdotes of symbol usage apart from any corpus of data that would make it possible to evaluate the significance of such anecdotes. Thus, Petitto and Seidenberg (1979; Seidenberg \& Petitto, 1979) have argued persuasively that it is difficult to tell whether the examples presented really reflect the apes' overall usage. For example, although a chimpanzee might appropriately sign "coffee" as it sees someone walk past with some coffee, such an occurrence means little if, on many other occasions, the chimpanzee signs "coffee" either in an inappropriate context, or in a situation where it is not obvious why the coffee sign should be used. The observations presented in this study can be evaluated against the backdrop of formal tests with the symbols, and a corpus that reveals their overall usage and accuracy. Specific data for any specific symbol, detailing its overall usage rate and type of usage are available on request.

Although we recognize that the number of subjects involved in the present study is small, some preliminary species' contrasts nonetheless are in order. Among the many performance differences that have emerged between common and pygmy chimpanzees reared by people and exposed to a graphic symbol communication system, the most striking to those who have worked daily with both species is the ease with which Kanzi and Mulika have comprehended that lexigrams could be used as a mode of symbolic communication to communicate about absent referents and events. Sherman and Austin did not spontaneously form associations between lexigrams and objects as did Kanzi and Mulika. Even after such associations were carefully taught, further training was required to separate the communicative acts of naming and requesting, and still further training was required to develop proper receptive responses to lexigrams used by others. Not until Sherman and Austin had received 3 years of training did they begin to evidence a clear concordance between what they said and what they then did. Kanzi and Mulika seemed to spontaneously grasp the idea that lexigrams stood for objects and for events and that one used them to communicate information about those objects and events. They did not need to be taught to differentiate between naming and requesting, nor did they need to be taught receptive skills. Unlike Austin and Sherman, Kanzi's and Mulika's receptive skills typically preceded their productive skills. Because they learned words be-

Table 9

Routes of Travel Prior to Test

\begin{tabular}{lllll}
\hline - 4 days & -3 days & -2 days & -1 day & Test day \\
\hline Apple & Apple & Peanut & Apple & Apple \\
Peanut & Orange & Melon & Orange & Orange \\
Juice & Apple & Surprise & Juice & Juice $^{\mathrm{a}}$ \\
Surprise & Peanut & Tomato & Peanut & Hotdog \\
Apple & Juice & Peaches & Tomato & Melon \\
Orange & Tomato & Melon & Hotdog & Peanut \\
Surprise & Hotdog & Surprise & Apple & Jelly \\
Tomato & Melon & Tomato & Peanut & M\&M \\
Hotdog & Juice & Hotdog & Tomato & Egg \\
Peaches & Peanut & Blackberry & Surprise & Backfence \\
Raisins & Tomato & Raisin & Hotdog & Banana \\
Jelly & Mushroom & Egg & Peanut & Raisin \\
M\&M's & Peaches & Cherry & Juice & Blackberry \\
Sweet & Hotdog & & Peanut & Sweet \\
potato & Surprise & & Melon & potato \\
Raisins & Apple & & Surprise & Cherry \\
Apple & & & Hotdog & Peaches \\
& & & Raisin & Tomato \\
& & & Tomato & Surprise \\
\hline
\end{tabular}

a Juice and banana are both located at the same place. ${ }^{b}$ The experimenter selected this site. 
fore they began to use them, when usage did appear, it was usually appropriate from the start, just as is the case with normal children (Benedict, 1979). By contrast, Sherman and Austin (and other language-trained apes) have gone through a period of new-word usage in which the initial usages are incorrect and drop out, as the correct associations become formed through production.

Kanzi's and Mulika's mother, Matata, did not acquire symbols spontaneously. Although she did begin to learn with training, she nonetheless still evidenced far more difficulty than did Sherman and Austin. Her difficulties suggest that there may be a critical age in the pygmy chimpanzee, beyond which acquisition of a symbol system is very difficult. Such a limiting effect suggests that perhaps other rearing variables might account for the observed differences between Sherman and Austin as contrasted with Kanzi and Mulika. Differences in rearing environments between these animals did exist and are difficult to quantify. Nonetheless, the observations that Sherman and Austin needed training, and that they did not comprehend spoken English well, are in agreement with those of others who have reared common chimpanzees in human environments from infancy. This makes it unlikely that Sherman's and Austin's specific environment led to these deficiencies. However, infants of both species are presently being reared side by side in the same environment as Kanzi and Mulika to answer this question more thoroughly.

A second major difference between the species is Kanzi and Mulika's ability to comprehend spoken English words. Sherman and Austin responded to English only in situations that provided them contextual information, including the nonverbal glances and gestures of the speaker. Given the cues of context, intonation, and nonverbal gestures, they reacted appropriately to simple commands such as "don't do that," "wait," "it's your turn," or "open the door." However, if asked to retrieve a specific object, they became confused when more than one object was available and they were given only English input. They then relied on pointing gestures to indicate which object they were being asked to retrieve. These observations are in accord with those of Hayes and Hayes (1951) and Kellogg and Kellogg (1933) who home reared Pan troglodytes chimpanzees, and with the first author's observations of the home-reared chimpanzee, Lucy (Savage-Rumbaugh, 1986).

Kanzi's and Mulika's ability to comprehend single words is clearly not context dependent. It is important to note that at no time did anyone ever try to teach Kanzi or Mulika to respond to English commands, or to utter single words over and over to them. People spoke normally around them at all times. Their ability to respond to specific words, which they extracted from complex phrases, was completely unforeseen when the study began. The speech synthesizer was added to the keyboard after data were obtained that revealed comprehension of spoken words. To the degree that Kanzi and Mulika can comprehend even single words as communicative referential utterances, they are demonstrating a basis for language comprehension that was not available to Sherman, Austin, or Lana. Understanding that people use spoken words to stand for things and understanding what many of those words are give Kanzi and Mulika a decided advantage when they encounter lexigrams being used as symbols. Instead of having to learn what symbols are and how they function communicatively, they have only to learn to "read" the lexigrams or to pair them with the spoken words they already know. As Mulika's data illustrate, this process can occur at a very early age and can predate the fluent usage of the symbols. Thus the way in which pygmy chimpanzees acquire graphic symbols appears to be fundamentally different from the way in which common chimpanzees learn them.

A third difference is found in the specificity with which lexigrams are associated with referents. Sherman and Austin were readily inclined to acquire broad differentiations, such as between playing, eating, drinking, or grooming, but differentiations within these categories were not something that they spontaneously treated as important. Only when the training environment required attention to such differentiations did they become reliable. Much has been made of the ape's ability to form general categories (Gardner \& Gardner, 1984; Jolly, 1985), yet it was far easier for Sherman and Austin to learn general categorical terms than it was to form discrete item-symbol associations within categories. Additionally, they tended to drift toward using a single term for all items within a category. Had their training begun with symbols whose referents were maximally discriminable, such as eat, groom, play, and outdoors, instead of items such as orange, banana, and $M \& M$, their early learning would surely have been more rapid. Conceivably, they may not have even required training to learn such broad-based symbols, particularly if the position of the lexigram was permitted to be confounded with its appearance. However, as discriminations within such categories were attempted, it is likely that they still would have experienced considerable difficulty.

By contrast, differentiations between items such as juice and coke were made quite spontaneously by Kanzi and Mulika and no special effort was required to maintain them. When Kanzi did generalize the use of his symbols, it was typically because there was no lexigram for the similar item, not because he made "within category errors" (Gardner \& Gardner, 1971). Thus, once coke and juice were learned, Kanzi did not use these symbols interchangeably, nor was any review or drill required to help Kanzi maintain the proper association of each symbol with its referent. Austin and Sherman, however, consistently needed review on items whose referents were similar, such as orange drink and strawberry drink, juice and coke, or tickle and chase. Without such review, these lexigrams would begin to be used interchangeably, as though they did not refer to items that were significantly different from Sherman and Austin's viewpoint.

A fourth important difference between Kanzi and Sherman and Austin was Kanzi's ability to request that $A$ act on $B$, when he was neither A nor B. Sherman and Austin never formed requests in which someone other than themselves was the beneficiary of the request. The same was true of Nim. The ability to conceptualize and then to symbolically initiate complex forms of interaction between others would seem to be a precursor of syntactical structure, if not the basis itself for the occurrence of syntax.

\section{Conclusion}

Although we do not, with such a small sample, assert that these differences are universal, they are nevertheless striking and worthy of further research to sort out more carefully the 
variables of rearing and species. Presently, infants of both species are being reared side by side to address this question more effectively.

Why might two such closely related species differ so greatly in their capacity to acquire a functional symbolic communication system? Presently, there is no answer to this question. However, when such closely related ape species differ significantly in their ability to comprehend spoken speech, the many behavioral differences that exist between men and apes seem less of an anomaly. It is of course behavior, not anatomy, that changes most rapidly, and when an ape can, simply by virtue of human rearing, begin to comprehend human speech, the power of culture learning looms very large indeed. It would follow that if the capacity to understand speech is there, waiting to be tapped into, it would only take one animal who developed an innovative way to produce sounds to push the behavior of a feral group of apes toward the path of language.

Given that the animals involved in the present study are representative individuals of their species (and there is no reason to conclude otherwise) the pygmy chimpanzee appears to possess a far greater propensity for the acquisition of symbols than other apes. The unexpected findings of the present study serve to document both the value of and the need for comparative methods and data if we are to gain a valid biological understanding of advanced forms of cognitive adaptation, such as language.

\section{References}

Asano, T., Kojima, T., Matsuzawa, T., Kubota, K., \& Murofushi, K. (1982). Object and color naming in chimpanzees (Pan troglodytes). Proceedings of the Japan Academy, 58, 118-122.

Benedict, H. (1979). Early lexical development: Comprehension and production. Journal of Child Language, 6, 183-200.

Bloom, L., Hood, L., \& Lightbown, P. (1974). Imitation in language development: If, when, and why. Cognitive Psychology, 6, 380-420.

Clark, R. A. (1978). The transition from action to gesture. In A. Lock (Ed.), Action, gesture and symbol: The emergence of language (pp. 231-257). London: Academic Press.

Dewson, J. H. (1964). Speech sound discrimination by cats. Science, 144, 555-556.

Fouts, R. S. (1972). Use of guidance in teaching sign language to a chimpanzee (Pan troglodytes). Journal of Comparative and Physiological Psychology, 80, 515-522.

Fouts, R. S. (1973). Acquisition and testing of gestural signs in four young chimpanzees. Science, 180, 973-980.

Fouts, R. S., Chown, B., \& Goodin, L. (1976). Transfer of signed responses in American Sign Language from vocal English stimuli to physical object stimuli by a chimpanzee (Pan). Learning and Motivation, 7, 458-475.

Fouts, R. S., Hirsch, A. D., \& Fouts, D. H. (1982). Cultural transmission of a human language in a chimpanzee mother-infant relationship. In H. E. Fitzgerald, J. A. Mullins, \& P. Gage (Eds.), Child nurturance (Vol. 3, pp. 159-193). New York: Plenum.

Gardner, B. T., \& Gardner, R. A. (1971). Two-way communication with an infant chimpanzee. In A. M. Schrier \& F. Stollnitz (Eds.), Behavior of nonhuman primates (Vol. 4, pp. 117-184). New York: Academic Press.

Gardner, R. A., \& Gardner, B. T. (1984). A vocabulary test for chimpanzees. Journal of Comparative Psychology, 98, 381-404.

Gray, H. (1978). Learning to take an object from the mother. In A. Lock
(Ed.), Action, gesture and symbol: The emergence of language (pp. 159-182). London: Academic Press.

Hayes, C. (1951). The ape in our house. New York: Harper.

Hayes, K. J., \& Hayes, C. (1951). The intellectual development of a home-raised chimpanzee. Proceedings of the American Philosophical Society, 95, 105-109.

Herman, L. M., Richards, D. G., \& Wolz, J. P. (1984). Comprehension of sentences by bottlenosed dolphins. Cognition, I6, 129-219.

Hirsch-Pasek, K., Golinkoff, R., Fletcher, A., Beaubien, F., \& Cauley, K. (1985, October). In the beginning: One word speakers comprehend word order. Paper presented at the Boston Language Conference, Boston.

Jolly, A. (1985). The evolution of primate behavior. New York: Macmillan.

Kano, T. (1980). Social behavior of wild pygmy chimpanzees (Pan paniscus) of Wamba: A preliminary report. Journal of Human Evolution. 9. 243-260.

Kellogg, W. N., \& Kellogg, L. A. (1933). The ape and the child. New York: Whittlesey House.

Kuhl, P. K., \& Miller, J. D. (1975). Speech perception by the chinchilla: Voiced-voiceless distinction in alveolar plosive consonants. Science, $190,69-72$.

Kuroda, S. (1984). Interaction over food among pygmy chimpanzees. In R. L. Susman (Ed.), The pygmy chimpanzee: Evolutionary biology and behavior (pp. 301-324). New York: Plenum.

Lieberman, P. (1984). The biology and evolution of language. Cambridge, MA: Harvard University Press.

Lieberman, P., Crelin, E. S., \& Klatt, D. H. (1972). Phonetic ability and related anatomy of the newborn, adult human, Neanderthal man, and the chimpanzee. American Anthropologist, 74, 287-307.

Lock, A. (1978). Action, gesture and symbol: The emergence of language. London: Academic Press.

Lock, A. (1980). The guided reinvention of language. London: Academic Press.

McGrew, W. C. (1975). Patterns of plant food sharing by wild chimpanzees. In M. Sikondo, E. Kawai, \& A. Ehara (Eds.), Contemporary primatology (pp. 306-309). Basel, Switzerland: Karger.

McGrew, W. C., \& Tutin, C. E. (1978). Evidence for a social custom in wild chimpanzees? Man, 13, 234-251.

Miles, H. L. (1983). Apes and language: The search for communicative competence. In J. de Luce \& H. T. Wilder (Eds.), Language in primates (pp. 43-61). New York: Springer-Verlag.

Morse, P. A., \& Snowdon, C. T. (1975). An investigation of categorical speech discrimination by rhesus monkeys. Perception and Psychophysics, 17, 9-16.

Patterson, F. (1978). The gestures of a gorilla: Language acquisition in another pongid. Brain and Language, 5, 72-97.

Patterson, F., \& Linden, E. (1981). The education of Koko. New York: Holt, Rinehart and Winston.

Patterson, T. (1979). The behavior of a group of captive pygmy chimpanzees (Pan paniscus). Primates, 20,341-354.

Petitto, L. A., \& Seidenberg, M. S. (1979). On the evidence for linguistic abilities in signing apes. Brain and Language, 8, 162-183.

Premack, D. (1971). On the assessment of language competence in the chimpanzee. In A. M. Schrier \& F. Stollnitz (Eds.), Behavior of nonhuman primates (Vol. 4, pp. 185-228). New York: Academic Press.

Premack, D. (1976). Language and intelligence in ape and man. Hillsdale, NJ: Erlbaum.

Rice, M. (1980). Cognition to language: Categories, word meanings, and training. Baltimore, MD: University Park Press.

Rumbaugh, D. M. (Ed.). (1977). Language learning by a chimpanzee: The LANA project. New York: Academic Press.

Rumbaugh, D. M., \& McCormack, C. (1967). The learning skills of primates: A comparative study of apes and monkeys. In D. Stark, R. 
Schneiderm, \& H. J. Kuhn (Eds.), Progress in primatology (pp. 289306). Stuttgart, W. Germany: Fischer.

Sanders, R. J. (1985). Teaching apes to ape language: Explaining the imitative and nonimitative signing of a chimpanzee (Pan troglodytes). Journal of Comparative Psychology, 99, 197-210.

Savage-Rumbaugh, E. S. (1981). Can apes use symbols to represent their world? In T. A. Sebeok \& R. Rosenthal (Eds.), The clever Hans phenomenon: Communication with horses, whales, apes, and people. Annals of the New York Academy of Sciences, 364, 35-59.

Savage-Rumbaugh, E. S. (1984a). Pan paniscus and Pan troglodytes: Contrasts in preverbal communicative competence. In R. L. Susman (Ed.), The pygmy chimpanzee: Evolutionary biology and behavior (pp. 395-413). New York: Plenum.

Savage-Rumbaugh, E. S. (1984b). Verbal behavior at a procedural level. Journal of the Experimental Analysis of Behavior, 41, 223-250.

Savage-Rumbaugh, E. S. (1986). Ape language: From conditioned responses to symbols. New York: Columbia University Press.

Savage-Rumbaugh, E. S., Pate, J, L., Lawson, J., Smith, S. T., \& Rosenbaum, S. (1983). Can a chimpanzee make a statement? Journal of Experimental Psychology: General, 112, 457-492.

Savage-Rumbaugh, E. S., Rumbaugh, D. M., \& McDonald, K. (1985). Language learning in two species of apes. Neuroscience \& Biobehavioral Reviews, 9, 653-665.

Savage-Rumbaugh, E. S., Rumbaugh, D. M., Smith, S. T., \& Lawson, J. (1980). Reference: The linguistic essential. Science, 210, 922-925.

Savage-Rumbaugh, E. S., Sevcik, R. A., Rumbaugh, D. M., \& Rubert, E. (1985). The capacity of animals to acquire language: Do species differences have anything to say to us? Philosophical Transactions of the Royal Society of London, B 308, 177-185.

Savage-Rumbaugh, E. S., \& Wilkerson, B. J. (1978). Socio-sexual behavior in Pan paniscus and Pan troglodytes: A comparative study. Journal of Human Evolution, 7, 327-344.

Savage-Rumbaugh, E. S., Wilkerson, B. J., \& Bakeman, R. (1977). Spontaneous gestural communication among conspecifics in the pygmy chimpanzee (Pan paniscus). In G. H. Bourne (Ed.), Progress in ape research (pp. 97-116). New York: Academic Press.

Schusterman, R. J., \& Krieger, K. (1984). California sea lions are capable of semantic comprehension. The Psychological Record, 34, 3-23.
Seidenberg, M. S., \& Petitto, L. A. (1979). Signing behavior in apes: A critical review. Cognition, 2, 177-215.

Shotter, J. (1978). The cultural context of communication studies: Theoretical and methodological issues. In A. Lock (Ed.), Action, gesture and symbol: The emergence of language (pp. 43-78). London: Academic Press.

Sinnott, J. M., Beecher, M. D., Moody, D. B., \& Stebbins, W. C. (1975). Speech sound discrimination by monkeys and humans. Journal of the Acoustical Society of America, 48, 579-593.

Terrace, H. S. (1979). Nim. New York: Alfred A. Knopf.

Terrace, H. S. (1985). In the beginning was the "name." American Psychologist. 40, 1011-1028.

Terrace, H. S., Petitto, L. A., Sanders, R. J., \& Bever, T. G. (1979). Can an ape create a sentence? Science, 206, 891-900.

Thompson-Handler, N., Malenky, R. K., \& Badrian, N. (1984). Sexual behavior of Pan paniscus under natural conditions in the Lomako Forest, Equateur, Zaire. In R. L. Susman (Ed.), The pygmy chimpanzee: Evolutionary biology and behavior (pp. 347-368). New York: Plenum.

Trevarthen, C., \& Hubley, P. (1978). Secondary intersubjectivity: Confidence, confiding and acts of meaning in the first year. In A. Lock (Ed.), Action, gesture and symbol: The emergence of language (pp. 183-229). London: Academic Press.

van Lawick-Goodall, J. (1968). The behaviour of free-living chimpanzees in the Gombe Stream Reserve. Animal Behaviour Monographs, $1,161-311$.

Warden, C. J., \& Warner, L. H. (1928). The sensory capacities and intelligence of dogs, with a report on the ability of the noted dog "Fellow" to respond to verbal stimuli. Quarterly Review of Biology, 3, 1-28.

Waters, R. S., \& Wilson, W. A., Jr. (1976). Speech perception by rhesus monkeys: The voicing distinction in synthesized labial and velar stop consonants. Perception and Psychophysics, 19, 285-289.

Wrangham, R. W. (1979). Sex differences in chimpanzee dispersion. In D. A. Hamburg \& E. R. McCown (Eds.), The great apes (pp. 481489). Menlo Park, CA: Benjamin/Cummings.

Yerkes, R. M., \& Learned, B. W. (1925). Chimpanzee intelligence and its vocal expressions. Baltimore, MD: Williams and Wilkins. 
Appendix

\section{Utterances and Context on One Randomly Selected Morning}

One morning was randomly selected from the data base to construct an Appendix that would illustrate the kinds of utterances that Kanzi and Mulika produce in the context of daily events. Because of space constraints, all utterances could not be included; however, the full Appendix is available on request. Each utterance is described in context along with some information about the daily routine, and the particular events surrounding the utterance. All keyboard utterances are underlined.

The purpose of this Appendix is not to offer data, because it is but one randomly selected morning, rather it is to present a brief view of the way in which Kanzi and Mulika use the keyboard. It should be kept in mind, however, that symbol usage is highly variable from day to day and at least a month's worth of utterances would be required to develop a realistic picture of keyboard usage.

\section{Utterances, Coding, and Comments}

Utterance. Shortly after the chimpanzees wake up, Bill enters their housing area. Following Bill's arrival Kanzi goes to the keyboard and requests "surprise." Bill responds, "yes surprise" (using both spoken English and the keyboard). Bill then relays Kanzi's request to Liz who is in an adjacent room. Liz selects a candy chocolate mint that she had brought for herself and gives it to Kanzi.

Coding. This utterance is coded as a spontaneous correct request because Bill had not mentioned surprises that morning.

Comment. When Kanzi asks for surprises, he is often told "no" (otherwise he would probably ask for them constantly). On occasions when we agree to obtain a surprise, we either go to the surprise location in the woods, or try to find something new around the lab that he has not seen before. Surprises are both food and nonfood items. Nonfood surprises include visits from strangers, new toys, and trips to special places.

Kanzi eagerly takes the surprise and after consuming it, is ready to play, which he evidences by running over and tugging on Bill and running away. Bill responds by chasing and tickling Kanzi, and Mulika also joins in. Matata observes. When Bill begins to tire of this activity and wishes to change it to a quieter interaction he uses the keyboard (and English) to request "grooming." In response, Mulika goes over to Matata and begins grooming her.

Utterance. After a bit, Kanzi indicates that he is ready to travel in the woods by touching "peaches go." It is still chilly out, as fall has just started to arrive so Kanzi is told, both in English and at the keyboard, that he will get to go out a little bit "later." (On warm mornings, this request would have been complied with.)

Coding. This utterance is scored as a spontaneous correct request because Bill had not mentioned peaches or going prior to Kanzi's request. Bill, Kanzi and Mulika continue watching slides and playing intermittently. Even though Kanzi is not allowed to take Bill to peaches, Bill scores this request as correct because Kanzi has done so many times in the past and the request is an appropriate one. Moreover, Kanzi gestures toward the door, indicating that he knows they will have to go out to obtain peaches.

Comment. Later is not a symbol that Kanzi uses, but he seems to understand something about its usage, in that he does not generally repeat his request for some time.

Utterance. Twenty to thirty minutes later Kanzi again indicates that he is ready to travel, this time by suggesting "peanuts." He does not indicate "go" as he did before, but again gestures toward the door. It is now warm and so Kanzi, Mulika, Liz, Bill, and Patty go outside. Kanzi leads the way to the trailer where peanuts are found.
Coding. This utterance is scored as a spontaneous correct request because Bill had not mentioned peanuts that morning. A concordance is also scored because Kanzi leads everyone to the trailer, where peanuts are located.

Receptive Response. At the trailer, Liz recalls that she saw a snake near there last weekend, and she decides to ask Kanzi, in English, to show Patty (who was not there the day this snake was found) where they had seen the snake. Prior to Liz's suggestion, Kanzi has been dallying around the front of the trailer, casually eating peanuts. Immediately after hearing Liz's request, (Liz uses English to convey this idea, while pointing to the snake lexigram on the keyboard) Kanzi goes over to Patty, takes her by the hand and leads her about $400 \mathrm{ft}(120 \mathrm{~m})$ to the location where the snake was seen the previous week. Kanzi and Patty look around the area carefully.

Coding. This is scored as a positive instance of receptive comprehension of the snake lexigram (and a note is made that both the lexigram and English were used.)

Utterance. Bill and Liz follow along as Kanzi takes Patty to where the snake was seen. They are carrying the peanuts and eating them as they walk. After ascertaining that no snake is in the vicinity Kanzi looks over at his keyboard and vocalizes "ii uh" to Bill. Bill (using only English) asks Kanzi if he trying to say "peanut." Kanzi responds by approaching the keyboard and touching "peanut." Bill shares some of the peanuts with Kanzi.

Coding. This utterance is scored a spontaneous correct request, because Bill had not used the keyboard to indicate "peanut" in his query. Kanzi often produces the "ii uh" vocalizations for peanuts, but because it is difficult for human listeners to understand, he is asked to clarify it through use of the keyboard.

Comment. We have begun to notice that Kanzi seems to be trying to imitate some spoken English words, albeit in a rather crude fashion. However, some sounds occur much more often in some situations than others, such as the usage of "ii uh" when Kanzi wants peanuts. However, Kanzi makes many noises which are very similar to "ii uh" and it is difficult to distinguish them if one is not listening for a particular sound. We are currently gathering data on Kanzi's use of vocalizations to determine whether or not there is evidence to support the view that he does, at times, try to imitate human speech. Such sounds are not part of the normal Pan paniscus vocal repertoire.

Utterance. After playing chase with Patty for some time, Kanzi stops to initiate a chase game between Liz and Patty. He conveys this wish by pulling Liz's hand a short distance toward Patty, touching "chase" at the keyboard, then tapping Patty on the chest.

Coding. This is scored as a spontaneous correct request because neither Liz nor Patty have suggested this themselves and is entered in the data as "person(g) chase person(g)."

Utterance. Kanzi observes Liz and Patty play, and then changes the game again by touching "key chase." Because Kanzi does not gesture toward anyone, Liz presumes that he wants to have her chase him for the keys, so she gives her keys to Kanzi. Kanzi smiles, tucks the keys in between his thigh and his abdomen and runs off down the road glancing back at Liz and Patty to see if they are following him. Liz and Patty chase him down the road, but when they begin to tire they slow down to a walk.

Coding. This is scored as a spontaneous correct request because neither Liz nor Patty had mentioned keys or chasing prior to Kanzi's utterance.

Utterance. Kanzi seems disappointed when Liz and Patty stop chas- 
ing him and he runs back toward them and asks them to continue, by touching "chase" at the keyboard and then runs again down the road with the keys. They refuse, indicating "no chase" at the keyboard and commenting in English that they are tired and do not feel like chasing anymore. Kanzi, not wanting to take no for an answer, repeats his request in the same manner three more times. Finally, Liz states very emphatically "no chase," speaking firmly and tapping the symbols loudly. Kanzi just as firmly then replies "yes chase." Because Kanzi is not often so adamant, Liz and Patty give in and chase him for a little further down the road even though they are quite winded at this point.

Coding. These utterances are all coded as spontaneous correct requests.

Utterance. Once the chasing is over, Kanzi indicates that he would like to go back to the lab by touching "play yard" (which refers to the outdoor caging area behind the lab). He then starts off in the direction of the lab.

Liz disagrees with Kanzi, telling him "no play yard" at the keyboard while explaining to Kanzi in English that the others would rather go somewhere else.

Coding. This utterance is coded as a spontaneous correct statement because no one had mentioned the play yard before Kanzi and Kanzi seemed to be making more of a statement about his intended actions, rather than requesting to go the playyard.

Comment. As Liz starts to use the keyboard to tell Kanzi where she wants to go, Kanzi pulls the keyboard out of her hands and walks away with it. She has the impression that he does not want to listen to her suggestion regarding alternative locations.

Utterance. Once Kanzi has the keyboard, he rushes a little ways ahead of the group, puts the keyboard down on the ground and touches "no play yard no play yard." Kanzi seemed to saying this to himself, as he did not look up at Liz, Patty, or Bill as he made this remark.

Coding. This is scored as a spontaneous imitated comment.

Comment. Liz, Bill, and Patty respond in English, "Yes, you are right Kanzi, we are not going to go the play yard.' Following the above remark, Kanzi continues on down the road toward the lab, until he comes to the perimeter gate. Just inside the gate, the road splits and it goes off toward the woods in one direction and toward the lab in the other direction. Upon reaching the gate, Kanzi suggests using the keys to open it up by gesturing toward Liz's keys and then to the padlock on the gate.

Utterance. Once everyone is through the gate, Kanzi touches "play yard mushroom trail" and starts off toward the play yard. Liz agrees, commenting "Yes, go play yard mushroom trail" in English and at the keyboard.

Coding. This is scored as a spontaneous correct statement.

Comment. Given Kanzi's location at the time this remark is made, there are basically two routes to the mushroom trail area, once which goes through the woods, and one which goes past the play yard. Liz presumes that Kanzi is indicating they should go to the mushroom trail by taking the route that passes by the play yard (as opposed to one which goes through the woods) particularly because he had just asked to go to the play yard and was told the others in the group wanted to go elsewhere. (Both routes are about the same distance, and Kanzi often specifies routes by using two location names together, using one location that is en route to another.)

As they start off in the direction of the playyard, a large stranger comes down the road in a big loud truck and heads toward the lab (it is a repair man arriving to install electrical conduit at the lab). This seems to make Kanzi a bit hesitant with regard to his plans to travel toward the lab. His hair begins to puff out and he tugs on the keyboard. (Because people generally carry the keyboard tucked under an arm as they travel, it is not always readily available when Kanzi would like to say smething. Kanzi has come to tug gently on the keyboard to indicate that he wants to use it in such situations. People generally stop and open up the key- board so that all three panels are visible to Kanzi in response to such tugging.) Because Liz is carrying Mulika, on this occasion she holds the keyboard up for him to see with only one panel facing outward. Kanzi looks at it and with a flick of his wrist gestures for Liz to show him another panel. She puts Mulika up on her shoulders to free her hands, and opens another panel. Kanzi again looks at it and then with a flick of his wrist, asks her to open the keyboard up completely.

Utterance. Kanzi finally finds the symbol he is searching for, he touches "juice" and gestures toward the trail that leads to the treehouse (where juice is located).

Coding. This is coded as a spontaneous correct statement and a correct concordance is scored.

Comment. By taking this trail, Kanzi will avoid encountering the stranger with the truck who just arrived at the lab. By going to the juice site, Kanzi will be at the location that has the highest trees and overlooks the lab from the woods. From this location, Kanzi will be able to watch what the stranger is doing at the lab, without being seen himself. Liz, Bill and Patty agree to go get juice and Kanzi leads directly to the treehouse where juice is located.

Upon arriving at the treehouse, Kanzi climbs up into the trees and looks back toward the lab. He then gestures toward the cooler, indicating that he would like to have it opened. Liz opens it and finds that the cooler is empty. Liz then suggests (by using English while pointing to the $M \& M$ and Flatrock lexigrams) that they go to Flatrock for M\&M's. Apparently Kanzi agrees, for he heads down the trail in the correct direction. (When Kanzi disagrees with such a suggestion he stays right where he is or he states an alternative food or location at the keyboard.)

They travel leisurely to Flatrock, stopping to look at interesting logs and occasionally climb trees along the way.

Utterance. As they pass Criss Cross Corners, Kanzi tugs on the keyboard and when it is opened for him he asks for "orange juice."

Coding. This is coded as a correct spontaneous request because no one has mentioned orange juice on this date prior to Kanzi's utterance.

Utterance. Mulika rushes over to the keyboard and requests "cheese."

Coding. This is scored as a correct spontaneous request because no one has mentioned cheese prior to Mulika's utterance.

Comment. The cooler is opened at Criss Cross Corners and is found to contain orange juice, cheese, and blackberries. (A number of additional foods were added to many locations after the blind test described in the body of the manuscript was administered. Foods are taken to each site at noon, while the chimpanzees are napping. Thus if a food is consumed during an afternoon, it will not be available if a site is visited the next morning before restocking has occurred.) Orange juice is given to Kanzi and cheese is given to Mulika.

Utterance. Kanzi sees the blackberries in the cooler as he is drinking his orange juice and uses the keyboard to request them by touching "Blackberries." As he touches the symbol, he produces a high-pitched food vocalization typically made by pygmy chimpanzees.

Coding. This is scored as a correct spontaneous request because no one has mentioned blackberries prior to Kanzi.

Utterance. Upon seeing Kanzi eating blackberries, Mulika rushes to the keyboard to request some for herself, before they are all gone. As she touches the blackberries symbol, she also vocalizes.

Coding. This is scored as a spontaneous correct utterance because Mulika was oriented away from the keyboard when Kanzi requested blackberries and thus she could not select the correct symbol simply by imitating Kanzi.

Comment. After eating the food, Kanzi climbs a tree and begins to take off his shirt, which he has been asked to wear because of the cool weather. He drops the shirt down to the ground. He is told, in English, 
that if he does not come down and put his shirt on that everyone is going to go away and leave him there alone. Kanzi come down and puts his shirt back on.

Utterance. Once his shirt is on, he approaches the keyboard and touches "eggs" and gestures down the trail in the appropriate direction.

Coding. This it scored as a correct spontaneous request and a correct concordance is also scored.

Comment. The egg location is enroute to the M\&M site (where $\mathrm{Liz}$ wants to go) so everyone agrees, saying in English (while pointing to the egg lexigram) that they will go to "eggs". Kanzi leads the way.

Along the way, he carries Mulika and plays with her as they travel on a long narrow bridge that crosses a muddy area. He also plays hide and seek, disappearing from sight in the dense underbrush along this part of the trail, only to reappear just as Liz and the other pass by large bushes. He then rushes past them to take the lead again and as he gets ahead, he hides once more. They comment along the way (in English) "Kanzi is hiding, Oh, where has he gone, Oh, how will we find him." This is a favorite game of Kanzi's that he often plays on this part of the trail. Upon arriving at the egg site, Kanzi consumes three eggs with great relish.

Utterance. Shortly after everyone settles down, Mulika looks at the bag of blueberries which Liz is holding. She gestures toward the bag and uses the keyboard to request "blueberries."

Coding. This is coded as a correct spontaneous request.

Utterance. After hungrily eating the handful of blueberries, Mulika goes to the keyboard and asks for more "blueberries." Realizing that she is very hungry for blueberries, Liz gives her the whole bag.

Coding. This is coded as a correct spontaneous request.

Utterance. Once Kanzi notices that Mulika has all the blueberries he approaches the keyboard and requests an "apple." The cooler is opened and apples are found. Kanzi is given an apple, which he takes, and then he climbs high in the tree, where he sits and basks in the sun, eating the apple.

Coding. This is coded as a spontaneous correct request because at least $15 \mathrm{~min}$, and a number of utterances have intervened since Liz's use of the apple lexigram to designate her intention to travel to the site.

Comment. Liz decides to build a fire so that everyone can get thoroughly warm. She announces this to Mulika by using English while pointing to the stick and campfire lexigrams. Liz returns about $10 \mathrm{~min}$ later with a large batch of sticks and begins to start a fire.

Utterance. Upon seeing the sticks which Liz has brought back, Mulika goes to the keyboard and searches for several minutes. Finally finding the lexigram she wants, she indicates "stick" and gestures toward the pile of sticks that Liz has brought back.

Coding. This is coded as a spontaneous imitated request because Liz had used the stick lexigram before she left to gather the sticks.

Comment. Upon receiving the sticks, Mulika begins to use them to construct a nest. After allowing Mulika to play with the sticks for about 15 min, Liz decides to go ahead and build the fire and tells Mulika, using English, that she needs the sticks and she pulls them away from
Mulika. (There are sticks everywhere in the woods, but Mulika wants the specific sticks that $\mathrm{Liz}$ has gathered.)

Utterance. Mulika then whimpers and goes to keyboard and again requests "stick."

Coding. This is coded as a spontaneous correct imitated utterance.

Comment. Since Mulika wants the sticks so badly, Liz returns them to her and goes to gather more for the fire. After the fire is built, Mulika loses interest in building a nest and comes over to join Bill, Liz, and Patty.

Receptive response. Bill uses English (while pointing to the bite lexigram) to tell Mulika that he would like to playbite with her. She immediately rolls into his lap, covering her head with her hands and looks up at Bill with a play-face expression.

Coding. Because Mulika's posture and expression suggested that she understood what Bill wanted to do, this is scored as a correct receptive response.

Utterance. Kanzi looks down from the tree as Bill and Mulika start to play and decides that he would like to join in. He comes down and indicates "bite" at the keyboard and then gestures to Mulika to indicate that he would like to bite her tummy also.

Coding. This is scored as a spontaneous imitated correct statement because Bill used the bite lexigram prior to Kanzi.

Comment. Bill stops biting Mulika to give Kanzi a chance. Kanzi bites her on the tummy while she laughs loudly.

Utterance. Kanzi then reinitiates the original plan to go to M\&Ms, by going to the keyboard and indicating "M\&Ms" and gesturing down the trail toward M\&Ms.

Coding. This is scored as a correct spontaneous request with a correct concordance.

Comment. Kanzi watches while Bill and Liz put out the fire and then he leads all the way to Flatrock.

Utterance. Upon ariving at Flatrock, Kanzi requests "M\&Ms." The bag at the site is opened and $20 \mathrm{M} \& \mathrm{Ms}$ are found. They are all given to Kanzi who retires to the hammock to eat them one at a time.

Coding. This is coded as a correct spontaneous request.

Utterance. After Kanzi finishes the M\&Ms he decides that he is thirsty, so he goes over to the keyboard and indicates "water" and looks at Liz. Liz gets a canteen out of her backpack and gives Kanzi a drink of water.

Coding. This is scored as a spontaneous correct request.

Comment. It is now noontime and Liz and Bill, using English (while pointing to the go colony room Matata lexigrams) tell Kanzi and Mulika that it is time to go back to the lab and visit their mother and take a nap. Kanzi climbs on Bill's shoulders and Mulika climbs on Liz's shoulders and they all head back to the lab. On arrival they all settle down for a short grooming bout, then they build a large nest of blankets and go to sleep.

Received October 8, 1985

Revision received March 31, 1986 